\title{
DNA methylation repels binding of hypoxia-inducible transcription factors to maintain tumor immunotolerance
}

Flora D’Anna ${ }^{1,2+}$, Laurien Van Dyck ${ }^{1,2+}$, Jieyi Xiong ${ }^{1,2+}$, Hui Zhao ${ }^{1,2 \dagger}$, Rebecca V. Berrens ${ }^{3,4}$, Junbin Qian ${ }^{1,2}$, Pawel Bieniasz-Krzywiec ${ }^{1,5}$, Vikas Chandra ${ }^{6}$, Luc Schoonjans ${ }^{1,7,8}$, Jason Matthews ${ }^{9}$, Julie De Smedt ${ }^{10}$, Liesbeth Minnoye ${ }^{1,2}$, Ricardo Amorim ${ }^{1,5}$, Sepideh Khorasanizadeh 6 , Qian Yu ${ }^{11}$, Liyun Zhao ${ }^{11}$, Marie De Borre ${ }^{11}$, Savvas N. Savvides ${ }^{12,13}$, M. Celeste Simon ${ }^{14,15}$, Peter Carmeliet ${ }^{1,7,8}$, Wolf Reik ${ }^{3,16,17,18}$, Fraydoon Rastinejad ${ }^{6,19}$, Massimiliano Mazzone ${ }^{1,5}$, Bernard Thienpont ${ }^{1,2,11^{*}}$ (i) and Diether Lambrechts ${ }^{1,2^{*}}$

\begin{tabular}{l}
\hline${ }^{*}$ Correspondence: bernard. \\
thienpont@kuleuven.be; diether. \\
lambrechts@vib-kuleuven.be \\
${ }^{\dagger}$ Flora D'Anna, Laurien Van Dyck, \\
Jieyi Xiong and Hui Zhao \\
contributed equally to this work. \\
${ }^{1}$ Center for Cancer Biology, VIB, \\
3000 Leuven, Belgium \\
Full list of author information is \\
available at the end of the article
\end{tabular}

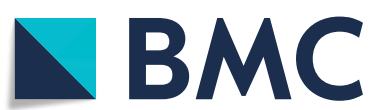

\begin{abstract}
Background: Hypoxia is pervasive in cancer and other diseases. Cells sense and adapt to hypoxia by activating hypoxia-inducible transcription factors (HIFs), but it is still an outstanding question why cell types differ in their transcriptional response to hypoxia.

Results: We report that HIFs fail to bind CpG dinucleotides that are methylated in their consensus binding sequence, both in in vitro biochemical binding assays and in vivo studies of differentially methylated isogenic cell lines. Based on in silico structural modeling, we show that 5-methylcytosine indeed causes steric hindrance in the HIF binding pocket. A model wherein cell-type-specific methylation landscapes, as laid down by the differential expression and binding of other transcription factors under normoxia, control cell-type-specific hypoxia responses is observed. We also discover ectopic HIF binding sites in repeat regions which are normally methylated. Genetic and pharmacological DNA demethylation, but also cancer-associated DNA

hypomethylation, expose these binding sites, inducing HIF-dependent expression of cryptic transcripts. In line with such cryptic transcripts being more prone to cause double-stranded RNA and viral mimicry, we observe low DNA methylation and high cryptic transcript expression in tumors with high immune checkpoint expression, but not in tumors with low immune checkpoint expression, where they would compromise tumor immunotolerance. In a low-immunogenic tumor model, DNA demethylation upregulates cryptic transcript expression in a HIF-dependent manner, causing immune activation and reducing tumor growth.
\end{abstract}

Conclusions: Our data elucidate the mechanism underlying cell-type-specific responses to hypoxia and suggest DNA methylation and hypoxia to underlie tumor immunotolerance.

Keywords: DNA methylation, Hypoxia, HIF, Cryptic transcripts, Immunotherapy, Cancer, Transcription factor binding (c) The Author(s). 2020 Open Access This article is licensed under a Creative Commons Attribution 40 International License, which permits use, sharing, adaptation, distribution and reproduction in any medium or format, as long as you give appropriate credit to the original author(s) and the source, provide a link to the Creative Commons licence, and indicate if changes were made. The images or other third party material in this article are included in the article's Creative Commons licence, unless indicated otherwise in a credit line to the material. If material is not included in the article's Creative Commons licence and your intended use is not permitted by statutory regulation or exceeds the permitted use, you will need to obtain permission directly from the copyright holder. To view a copy of this licence, visit http://creativecommons.org/licenses/by/4.0/. The Creative Commons Public Domain Dedication waiver (http://creativecommons.org/publicdomain/zero/1.0/) applies to the data made available in this article, unless otherwise stated in a credit line to the data. 


\section{Background}

DNA methylation is central to establishing and maintaining tissue-specific gene expression, and an important contributing factor to oncogenesis. We recently demonstrated that pervasive and ablating conditions of tumor hypoxia drive DNA methylation of tumor suppressor genes by reducing the activity of TET DNA demethylases [1]. An outstanding question is, however, if and how DNA methylation in turn also influences the response of tumors to (acute) hypoxia. Indeed, recent evidence suggests that, contrary to traditional concepts, DNA methylation generally does not directly impede transcription factor (TF) binding, but rather acts indirectly by synergizing with other epigenetic marks [2].

The hypoxia response is canonically executed by HIFs, which are heterodimeric TF complexes composed of an $\mathrm{O}_{2}$-labile $\alpha$-subunit (HIF $1 \alpha$, HIF $2 \alpha$ or HIF3 $\alpha$ ) and a stable $\beta$ subunit (HIF1 $\beta$ ). The constitutively expressed HIF $\alpha$ subunits are directly targeted for proteasomal degradation under normal oxygen tension (normoxia), but stabilized under limiting oxygen conditions (hypoxia), when they translocate to the nucleus to induce expression of hypoxia-responsive genes. This induction of hypoxia-responsive genes occurs rapidly, often within minutes following hypoxia [3]. In tumors, hypoxia is widespread and leads to transcriptional activation of numerous cancer hallmark genes involved in cell survival, angiogenesis, and invasion [4]. Interestingly, the impact of hypoxia differs among cell types. For instance, endothelial cells proliferate and migrate towards hypoxic regions, macrophages become immunosuppressive and $\mathrm{CD}^{+} \mathrm{T}$ cell activation is enhanced under hypoxia [5-8]. Also, tumors affecting different organs exhibit divergent phenotypic responses to hypoxia [6]. In line with this, concordance between HIF binding sites in MCF7 breast and 786-O renal cell carcinoma cell lines is only $40-60 \%$ [9]. This divergence is particularly intriguing because HIF $\alpha$ paralogues are often expressed at similar levels in different cell types, and because the consensus DNA sequence that binds HIF complexes, i.e., the hypoxia response element (HRE) RCGTG, does not differ between HIF $\alpha$ paralogues or cell types. Thus, although the concept that genes induced by hypoxia differ dramatically between cancer and cell types is wellestablished [3, 10-12], the reason for these divergent responses and expression programs is poorly understood.

One possibility is that the underlying cell-type-specific patterns of chromatin determine which HIF target genes are accessible and hence become expressed following acute hypoxia. Interestingly, HIFs are recruited to genes that are already expressed in normoxic cells [12], suggesting that perhaps DNA methylation could determine accessibility of the HIF complex to the RCGTG core sequence. HIF binding to the erythropoietin promoter was indeed suggested to be sensitive to DNA methylation [13], but this observation relied on gel shift binding assays, which are known to poorly reflect the authentic setting in cells. Indeed, the binding of the transcriptional repressor CTCF also appeared to be methylation-sensitive in gel shift binding assays [14], but analyses of its binding preference in living cells mostly failed to reveal methylation sensitivity [15]. We therefore set out to investigate whether DNA methylation directly repels HIF binding in living cells, and whether cell-type-specific DNA methylation patterns established under normoxic conditions determine genome-wide HIF binding profiles, defining the response to hypoxia. 


\section{Results}

\section{DNA methylation of HRE sites anti-correlates with HIF binding}

To investigate the role of DNA methylation in HIF binding, we stabilized HIFs in MCF7 breast cancer cells by culturing them under acute hypoxia $\left(0.5 \% \mathrm{O}_{2}\right.$ for $16 \mathrm{~h}$; Additional file 1 : Fig. S1a and S2, and "Methods"), conditions that are insufficient to drive hypoxia-induced hypermethylation [1]. We next performed chromatin-immunoprecipitation coupled to high-throughput sequencing (ChIP-seq) for HIF1 $\beta$, which is the obligate dimerization partner of HIF1 $\alpha$, HIF2 $\alpha$, and HIF3 $\alpha$. Model-based analysis for ChIP-seq (MACS) [16] revealed 7153 HIF1 $\beta$ binding peaks (Fig. 1a, Table S1). These were high-quality, bona fide HIF binding regions: they were 4.6-fold enriched for the HRE motif (RCGTG), enriched near genes involved in the hypoxia response, $>90 \%$ overlapping with peaks identified in another HIF1 $\beta$ ChIP-seq dataset on MCF7 cells and reproducibly detected in independent repeats (Additional file 1: Fig. S1b-d).

To assess methylation in these 7153 HIF1 $\beta$ binding peaks, we performed target enrichment-based bisulfite sequencing (BS-seq) on DNA extracted from normoxic MCF7 cells, in which HIF is inactive, obtaining $>40 \times$ coverage for $\sim 86 \%$ of the HIF $1 \beta$ binding peaks identified by ChIP-seq. The methylation level at these peaks was invariably low $(4.95 \pm 0.15 \%)$ compared to average CpG methylation levels detected in the genome $\left(61.6 \pm 0.07 \%\right.$, Wilcoxon test $P<2.2^{-16}$, Fig. $\left.1 \mathrm{~b}\right)$. Results were confirmed using another whole-genome BS-seq dataset (Fig. 1a) [18]. Also when quantifying methylation across all RCGTG motifs, including those located outside of HIF1 $\beta$ binding peaks, the inverse correlation between DNA methylation and HIF binding was confirmed (Fig. 1c). As BS-seq does not discriminate between 5-methyl $(5 \mathrm{mC})$ and 5-hydroxymethylcytosine [19], we confirmed by DNA immunoprecipitation with an antibody recognizing only $5 \mathrm{mC}(5 \mathrm{mC}$ DIP-seq) that HIF1 $\beta$ binding peaks were six fold depleted in $5 \mathrm{mC}$-DIP-seq reads (Fig. 1a). Moreover, methylation analysis of normoxic HIF1B-knockout MCF7 cells [20] revealed identical methylation patterns (Additional file 1: Fig. S1e-g), indicating that the unmethylated state of HIF1 $\beta$ binding sites is not due to baseline activities of HIF1 $\beta$ under normoxia. Importantly, identical results were obtained for murine embryonic stem cells (mESCs): the loci corresponding to the 4794 HIF1 $\beta$ binding sites identified in wild-type ESCs were unmethylated in normoxia, and this both in wild-type and Hiflb-knockout ESCs [21] (Additional file 1: Fig. S1h-j). Since cells were intentionally exposed only briefly to hypoxia $(16 \mathrm{~h})$, which fails to induce pronounced DNA methylation changes [1], these data suggest that regions to which HIF1 $\beta$ binds upon hypoxia are devoid of DNA methylation under normoxic conditions.

\section{Cell-type-specific DNA methylation of HREs determines HIF binding}

Different cell types respond differently to hypoxia. To assess whether cell-type-specific DNA methylation could underlie this phenomenon, we profiled DNA methylation and HIF1 $\beta$ binding in 2 additional cell lines (RCC4 and SK-MEL-28). A total of 20,613 HIF1 $\beta$ binding peak positions were detected across these cell lines (Additional file 3). For each cell line, HIF1 $\beta$ binding was annotated as "present" if the peak area showed $>4$-fold enrichment over the local read depth, and as "absent" if it showed < 2.5-fold enrichment; intermediate enrichment was annotated as unclassified (Additional file 3). When comparing cell lines using these criteria, HIF1 $\beta$ binding was shared by all 3 cell lines at 6152 sites, 


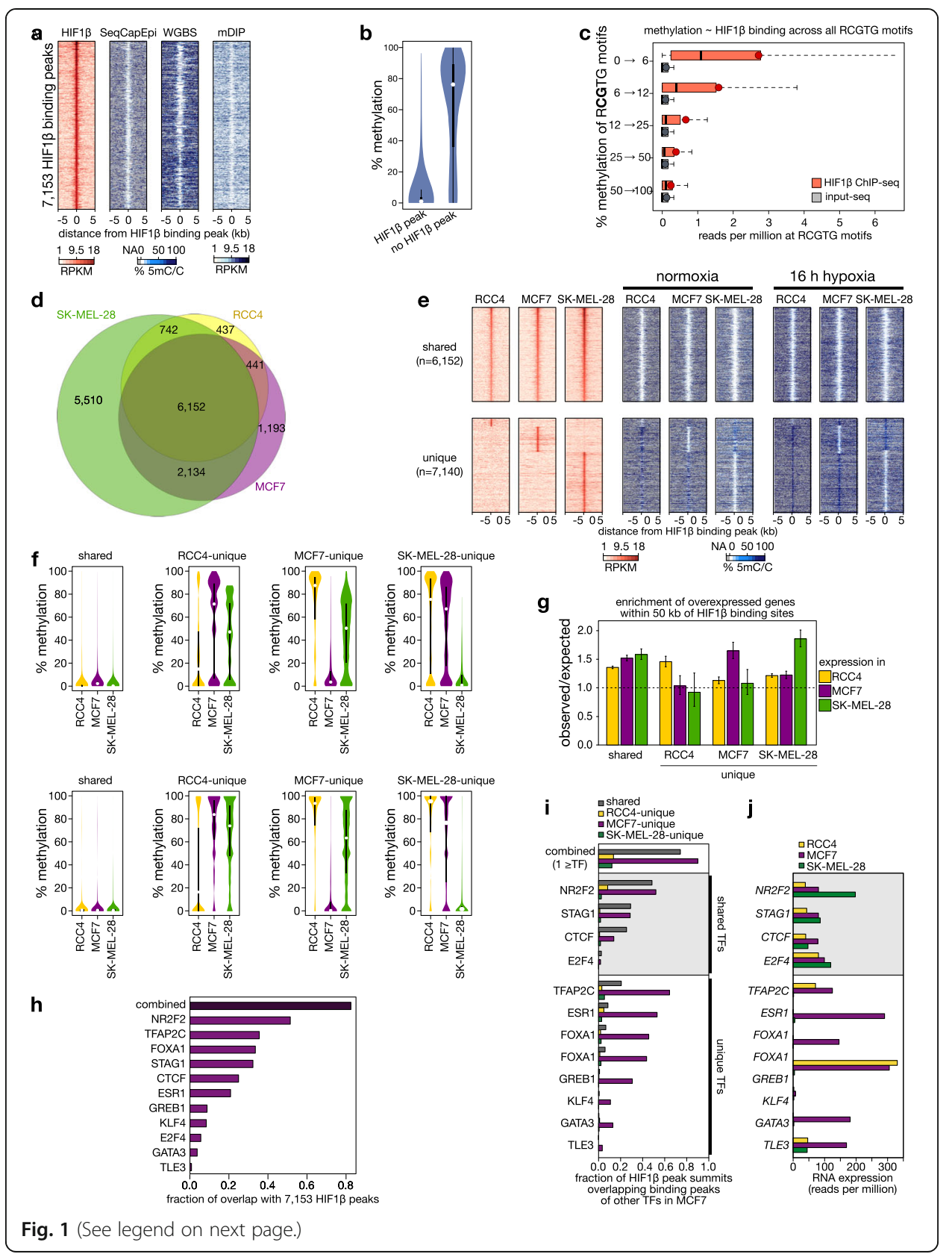


(See figure on previous page.)

Fig. 1 Methylation at HIF1 $\beta$ binding sites. a Heatmaps of HIF1 $\beta$ binding and DNA methylation for 7153 regions (identified using a stringent threshold of $P<10^{-15}$ in MACS) surrounding the HIF1 $\beta$ ChIP-seq peak summit ( $\pm 5 \mathrm{~kb}$ ). Heatmaps depict reads per kb per million reads (RPKM) of HIF1 $\beta$ ChIP-seq and of $5 \mathrm{mC}$ DNA IP-seq (mDIP), and \% DNA methylation as estimated by SeqCapEpi BS-seq or whole-genome BS-seq (respectively, SeqCapEpi and WGBS). HIF1 $\beta$ binding was assessed after $16 \mathrm{~h}$ of $0.5 \% \mathrm{O}_{2}$ (hypoxia) and DNA methylation under $21 \% \mathrm{O}_{2}$ (normoxia). b Violin plots of the methylation level inside and outside HIF1 $\beta$ binding peaks, as estimated by SeqCapEpi BS-seq. c Sequencing read depth of HIF1ß ChIP and its input, at all RCGTG sequences in MCF7 cells, stratified for methylation at the CG in the core RCGTG sequence. Shown are boxplots for all RCGTG's in the human genome for which $>10 \times$ coverage was obtained after SeqCapEpi BS-seq, with dark red dots denoting averages. See Additional file 1: Fig. S5 for additional QC of ChIP-seq data and Additional file 2 for more details about HIF1 $\beta$ binding peak locations. d Venn diagram of 20,613 shared and unique HIF1 $\beta$ binding sites detected across 3 cell lines. Only stringent binding sites $\left(P<10^{-15}\right)$ are shown. Binding sites showing intermediate levels of HIF1 $\beta$ ChIP-seq enrichment in 1 or 2 cell lines are unclassified and not shown here $(n=445,2812$ and 887 peaks, detected in SK-MEL-28, RCC4, and MCF7 respectively). e Heatmaps of HIF1 $\beta$ binding (red) and DNA methylation as estimated using SeqCapEpi BSseq (blue) at regions flanking the HIF1 $\beta$ ChIP-seq peak summit ( $\pm 5 \mathrm{~kb}$ ). (top) HIF1 $\beta$ binding peaks shared between the 3 cell lines. (bottom) HIF1 $\beta$ binding peaks unique to each cell line. Heatmaps depict RPKM of HIF1 $\beta$ ChIP-seq and \% DNA methylation. HIF1 $\beta$ binding was assessed after $16 \mathrm{~h}$ of $0.5 \% \mathrm{O}_{2}$ (hypoxia) and DNA methylation under $21 \% \mathrm{O}_{2}$ (normoxia) or after $16 \mathrm{~h}$ of $0.5 \% \mathrm{O}_{2}$ (hypoxia). $\mathbf{f}$ Quantification of the methylation level at HIF1 $\beta$ binding peak summits $\pm 100 \mathrm{bps}$, for peaks that are shared between or unique to one of the 3 cell lines grown under $21 \% \mathrm{O}_{2}$ (normoxia, top) or after $16 \mathrm{~h}$ of $0.5 \% \mathrm{O}_{2}$ (hypoxia, bottom). $\mathbf{g}$ Enrichment of gene expression (observed/expected) upon hypoxia per cell line, for genes associated with HIF1 $\beta$ binding sites (within $50 \mathrm{~kb}$ ) that are shared between or unique to one of the three cell lines, as labeled on the $X$-axis. $\mathbf{h}$ Fraction of HIF1 $\beta$ peaks overlapping with the binding peaks of individual transcription factors [17], or with any of the 11 transcription factors profiled in MCF7 cells ("combined"). $\mathbf{i}$ Overlap between HIF1 $\beta$ binding peaks and other transcription factor binding sites detected in MCF7 cells. Shown are fractions of HIF1 $\beta$ binding peaks shared between (gray) or unique for a cell line (colored). $\mathbf{j}$ mRNA expression level of transcription factors in each cell line, as determined using RNA-seq. Transcription factors expressed in all three cell lines are highlighted as "shared TFs" with a light gray box

and unique for an individual cell line at 7140 sites (437, 1193, and 5510 unique sites, respectively for RCC4, MCF7, and SK-MEL-28) (Fig. 1d, Additional file 1: Fig. S1k-1). Crucially, when assessing DNA methylation both under normoxia and under acute hypoxia, HIF1 $\beta$ binding peaks unique to individual cell lines were unmethylated in cells where the binding site was active, while active HIF1 $\beta$ binding peaks shared between all cell lines were unmethylated in all cell lines (Fig. 1e, f, Additional file 1: Fig. S1m-n). This strict correlation suggests that DNA methylation underlies the cell-type-specific response to hypoxia. Differences in DNA methylation and concomitant HIF binding also appeared functional, as transcriptome profiling under normoxic and hypoxic conditions revealed that genes with a flanking HIF1 $\beta$ binding peak unique to one cell line were more frequently increased in expression under hypoxia in that cell line (Fig. 1g).

\section{DNA methylation determines HIF binding independently of other chromatin marks}

To analyze whether other epigenetic modifications similarly correlate with HIF binding, we analyzed public ENCODE data for MCF7 cells [22] (no data are available for RCC4 and SK-MEL-28). Particularly, we investigated marks of heterochromatin (H3K9me3, H3K27me3), active promoters (H3K4me3, H3K9ac, H3K14ac), active enhancers (H3K4me1, H3K27ac), open chromatin (FAIRE), and active transcription (RNA Pol-II). Although some histone marks were enriched in a subset of HIF1 $\beta$ binding peaks, none were consistently found at all active HIF1 $\beta$ binding peaks, especially when looking outside of CpG islands (Additional file 1: Fig. S3a). The previously reported co-occupancy with RNA polymerase II or open chromatin was also not consistently found at all active 
HIF1 $\beta$ binding peaks [12]. This was confirmed in linear regression analyses assessing how each mark individually predicts HIF1 $\beta$ binding in MCF7 cells. DNA methylation $\left(R^{2}=0.43\right)$ outperformed all other marks, with marks of active chromatin such as RNA polymerase II occupancy, H3K4me3, open chromatin, and H3K27ac showing poor correlations ( $R^{2}$ resp. 0.11, 0.11, 0.04 and 0.04). When combining all marks in one model, the total $R^{2}$ was 0.47 , with DNA methylation contributing to $67.5 \%$ of the predictive power (partial $R^{2}=0.32$ ). In line with this, omitting DNA methylation from the model reduced the total $R^{2}$ by more than half, to 0.21 (Additional file 1: Fig. S3b).

We also assessed whether more general differences in chromatin states (using ChromHMM [23]) underlie differential HIF binding. This revealed that while shared HIF $1 \beta$ binding sites were more frequent in promoters, sites unique to MCF7 were more frequent in enhancers, and sites inactive in MCF7 (but unique to RCC4 or SK-MEL-28) more frequent in MCF7-repressed chromatin (Additional file 1: Fig. S3c). In line with enrichment at open chromatin, HIF1 $\beta$ binding thus appears exclusive to active enhancers and promoters while depleted in areas of repressed chromatin. Finally, NOMe-seq data from MCF7 cells revealed that, while open chromatin regions were generally unmethylated, a significant fraction of open chromatin (7-19\%) in fact showed methylation (Additional file 1: Fig. S3d), providing a potential rationale for the relatively small contribution of open chromatin to predict HIF1 $\beta$ binding. Combined, these data show that in normoxia poised HIF binding sites are located in unmethylated regions that consist mostly of active, open chromatin but are not consistently marked by other epigenetic modifications.

\section{Other TFs determine the methylation landscape to guide HIF binding}

Interestingly, many of the HIF1 $\beta$ binding peaks overlapped with binding sites for other TFs. Specifically, out of the 7153 HIF1 $\beta$ binding peaks detected in MCF7 cells, 5903 overlapped with the binding site of at least one TF (83\%), out of a set of 11 TFs for which genome-wide binding site data were available in MCF7 cells [17] (Fig. 1h). This could indicate that these TFs, being already active under normoxic conditions, drive demethylation of HIF1 $\beta$ binding regions [24], thus setting the stage for HIF binding upon hypoxia. To further support this notion, we assessed whether these 11 TFs also bind at HIF1 $\beta$ binding peaks identified in RCC4 and SK-MEL-28 cells. Interestingly, TFs expressed by the 3 cell lines (e.g., CTCF or STAG1) co-localize in their binding with the shared HIF1 $\beta$ binding peaks. In contrast, TFs only expressed in MCF7 cells (e.g., ESR1 or GATA3) overlap in their binding sites only with MCF7-specific HIF1 $\beta$ binding peaks. Finally, binding of these 11 TFs in MCF7 did not overlap with HIF1 $\beta$ binding peaks unique to RCC4 or SK-MEL-28 (Fig. 1i, j). These data were replicated in an independent cell line (Additional file 1: Fig. S3e-g). Differential expression and binding of TFs between different cells is thus likely to shape the DNA methylation landscape and determine subsequent HIF binding.

\section{DNA methylation does not determine differential binding of HIF1a and HIF2a}

Comparison of our 7153 HIF1 $\beta$ peaks to previously published HIF1 $\alpha$ and HIF2 $\alpha$ ChIPseq data in MCF7 cells revealed that the methylation status of HIF1 $\beta$ binding peaks was independent of the HIF $\alpha$ binding partner, as HIF1 $\alpha$ - and HIF $2 \alpha$-bound DNA showed similar methylation levels (Additional file 1: Fig. S3h). Remarkably, there were 
differences in the chromatin profiles of HIF1 $\alpha$ - and HIF2 $\alpha$-bound regions: HIF $1 \alpha$ binding sites showed 1.37-fold higher average levels of the promoter mark H3K4me3, whereas levels of the enhancer mark H3K4me1 were 0.75-fold lower at HIF1 $\alpha$ binding sites than at HIF $2 \alpha$ sites (Additional file 1: Fig. S3i). Similarly, chromHMM analysis showed enrichment of HIF $1 \alpha$ at promoters and depletion at enhancers relative to HIF2 $\alpha$ (Additional file 1: Fig. S3j). Moreover, other TFs similarly differed in occupancy between HIF1 $\alpha$ - and HIF2 $\alpha$-specific sites: HIF2 $\alpha$ was enriched at MCF7-specific TF binding sites (which mostly correspond to cell-type-specific enhancers), and TFs shared between MCF7, RCC4, and SK-MEL-28 showed no enrichment of binding between HIF1 $\alpha$ and HIF2 $\alpha$ target sites (Additional file 1: Fig. S3f,k). In conclusion, the binding preferences of HIF $1 \alpha$ and HIF $2 \alpha$ differ, with HIF $1 \alpha$ being somewhat more promoterenriched and HIF2 $\alpha$ being more enhancer-enriched, but these preferences are not determined by differences in DNA methylation at their binding sites.

\section{DNA methylation directly repels HIF binding in cells}

To more firmly establish a causal link between DNA methylation and HIF binding, we excluded several confounders. Firstly, since our chromatin state analysis revealed that HIF preferentially binds active enhancers and promoters, which are known to carry low levels of methylation [24], we performed HIF1 $\beta$ ChIP-bisulfite sequencing (HIF1 $\beta$ ChIP-BS-seq). MCF7 cells were exposed to hypoxia; HIF1 $\beta$-bound DNA was immunoprecipitated and bisulfite-converted prior to sequencing to uncover its methylation pattern. This revealed that, while methylation levels of input DNA (not immunoprecipitated, bisulfite-converted DNA) were mostly low but with some sites displaying intermediate to high methylation levels, HIF1ß-bound DNA was invariably very low in methylation and this at all sites (Fig. 2a, Additional file 1: Fig. S4a).

Secondly, since TFs can drive demethylation of their binding sites both passively and actively, we excluded the possibility that DNA fragments bound by HIF would undergo DNA demethylation upon HIF binding. Indeed, HIF1 $\beta$ has previously been shown to actively recruit DNA demethylases [26]. However, HIF1 $\beta$ ChIP-BS-seq in hypoxic ESCs deficient for all DNA demethylases (Tet1, Tet2, and Tet3) showed results identical to those observed in wild-type MCF7 cells: HIF1ß-bound DNA was unmethylated compared to input DNA subjected to whole-genome BS-seq (Fig. 2b, Additional file 1: Fig. S4b).

Additionally, other (unknown) confounders related to the binding location of HIF, such as chromatin environment or sequence context, may contribute to preferential HIF binding to unmethylated DNA. To exclude this possibility, we generated isogenic murine ES cell lines in which a human HIF1 $\beta$ binding site-encoding DNA fragment was inserted that was either in vitro methylated or not (Fig. 2c). Following recombination, the difference in methylation state between both fragments was maintained (Additional file 1: Fig. S4c-d). HIF1 $\beta$ ChIP-qPCR revealed that methylation was sufficient to induce a 12.4-fold reduction in HIF1 $\beta$ binding in these isogenic cell lines (Fig. 2d).

Finally, to directly assess methylation sensitivity of HIF binding to unchromatinized DNA, we employed microscale thermophoresis and tested the binding of recombinant co-purified HIF $1 \alpha$-HIF $1 \beta$ and HIF $2 \alpha$-HIF1 $\beta$ heterodimers to double-stranded DNA oligonucleotides containing a methylated or unmethylated RCGTG motif. Importantly, HIF1 $\alpha$ - and HIF $2 \alpha$-containing heterodimers both showed a 15 -fold higher affinity $\left(K_{\mathrm{D}}\right)$ 


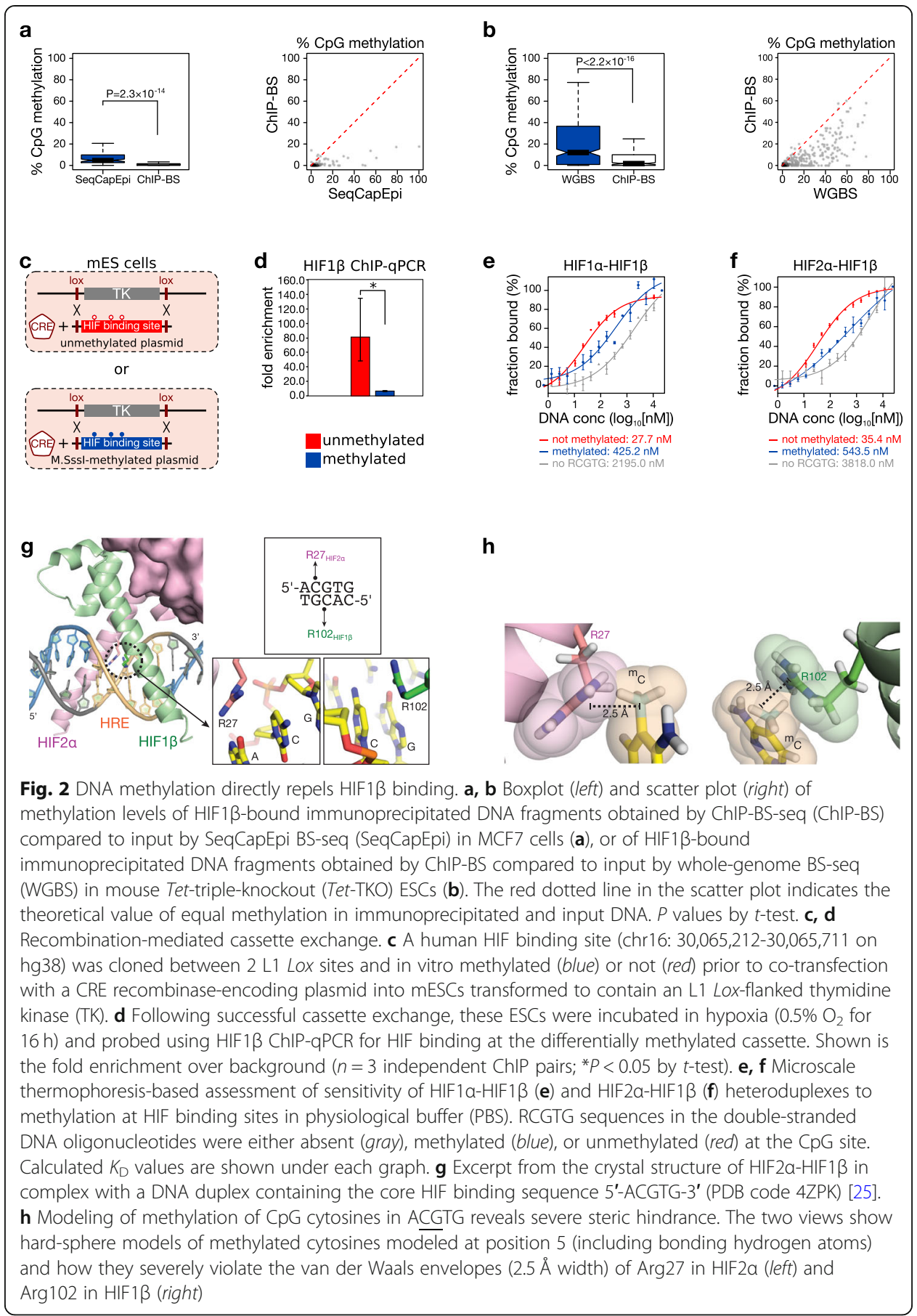

for an unmethylated than methylated RCGTG motif, thus confirming that methylation directly repels binding of HIF $1 \alpha-H I F 1 \beta$ and HIF $2 \alpha$-HIF $1 \beta$ heterodimers (Fig. 2e, f). Indeed, leveraging the crystal structure of the HIF $1 \alpha-$ HIF $1 \beta$ and the HIF $2 \alpha-H I F 1 \beta$ complexes bound to DNA [25], revealed that both cytosines in the CpG dinucleotide of the HIF binding sequence are snuggly accommodated via van der Waals interactions with the guanidine groups of Arg102 in HIF1 $\beta$ and Arg27 in HIF1 $\alpha$ or HIF2 $\alpha$, respectively (Fig. 2g) [25]. Methylation of any of the two cytosines either on the top or bottom strand would in a static model drastically violate the minimum $3.1 \AA$ length of van der 
Waals radii and would be poised to cause severe steric clashes with these two functionally important arginine residues in HIF1 $\alpha$ or HIF2 $\alpha$ (Fig. $2 \mathrm{~h}$ ).

\section{DNA demethylation enables ectopic HIF binding}

Next, we investigated which parts of the genome are protected from HIF binding by DNA methylation. For this, we compared HIF1 $\beta$ binding in hypoxic wild-type murine ESCs versus ESCs deficient for DNA methyltransferases (Dnmt-TKOs), which lack DNA methylation [27], using HIF1 $\beta$ ChIP-seq $(n=4$ replicates for each; for data quality assessment see Additional file 1: Fig. S5). This revealed a marked increase in the number of HIF1 $\beta$ binding peaks, from 7875 in wild-type to 9806 in Dnmt-TKO ESCs (Fig. 3a). Whole-genome BS-seq further revealed that, while shared binding peaks were unmethylated in both cell lines, Dnmt-TKO-specific HIF1 $\beta$ binding peaks had high methylation levels in wild-type ESCs (Fig. 3b).

All shared binding peaks were associated with a similar enrichment of the RCGTG motif (Fig. 3c), as well as with genes that were induced upon hypoxia (Fig. 3d). However, Dnmt-TKO-specific sites were more often distal to annotated transcription start sites (TSS) or regions of open chromatin, and more frequently in repressed chromatin regions of wild-type ESCs (Fig. 3e-g). Gene ontology analysis moreover failed to identify enrichment of hypoxia-related processes for Dnmt-TKO-specific binding peaks, in contrast to shared peaks (Fig. 3h). Thus, the majority of these Dnmt-TKO-specific binding peaks represents ectopic binding events.

\section{DNA methylation represses hypoxia-induced expression of retrotransposons}

Indeed, a substantial fraction of novel Dnmt-TKO-specific HIF1 $\beta$ binding peaks were found in repetitive genomic regions. Particularly, repeat class analysis revealed a 1.65fold increase in binding peaks near retrotransposons (2737 of 7875 (34.8\%) shared peaks versus 1106 of 1931 (57.3\%) Dnmt-TKO-specific peaks; Additional file 1: Fig. S6a). Although HIF1 $\beta$ binding events were frequently observed at LINEs and SINEs, only binding at long terminal repeats (LTRs) was enriched over a randomization of HIF1 $\beta$ binding site positions, and this both for all binding events and those distal to TSS (Fig. 3i). The bulk of this increase was ascribable to binding at the $5^{\prime}$-end of endogenous retrovirus K (ERVK) LTR sequences (Fig. 3j), with 344 of 1106 (31\%) novel repeat-binding peaks being at ERVKs versus only 3\% of randomly shuffled HIF1 $\beta$ binding sites. These were mostly at solitary LTRs (Additional file 1: Fig. S6b-e). Given that ChIP-seq analyses rely on uniquely mapping reads, which are inherently depleted at repeat regions, this enrichment is likely to represent an underestimate.

We then assessed whether a similar phenomenon is at play in cancer cell lines, and pharmacologically demethylated MCF7 cells using a non-cytotoxic [28] dose of 5-aza2 '-deoxycytidine (aza, $1 \mu \mathrm{M})$, necessary and sufficient for strongly reducing DNA methylation (Additional file 1: Fig. S6f). HIF1 $\beta$ ChIP-seq revealed that aza exposed 1236 new HIF1 $\beta$ binding peaks. These were all methylated in untreated MCF7 cells and showed a 2.5-fold reduced methylation in aza-treated cells (Fig. 4a-b). While HIF1 $\beta$ binding peaks in retrotransposons were already present in vehicle-treated MCF7 cells, novel aza-specific HIF1 $\beta$ binding peaks were 1.7 -fold enriched for retrotransposons ( $9.7 \%$ versus 16.4\%, respectively; Additional file 1: Fig. S6g). Again, these novel HIF1 $\beta$ 


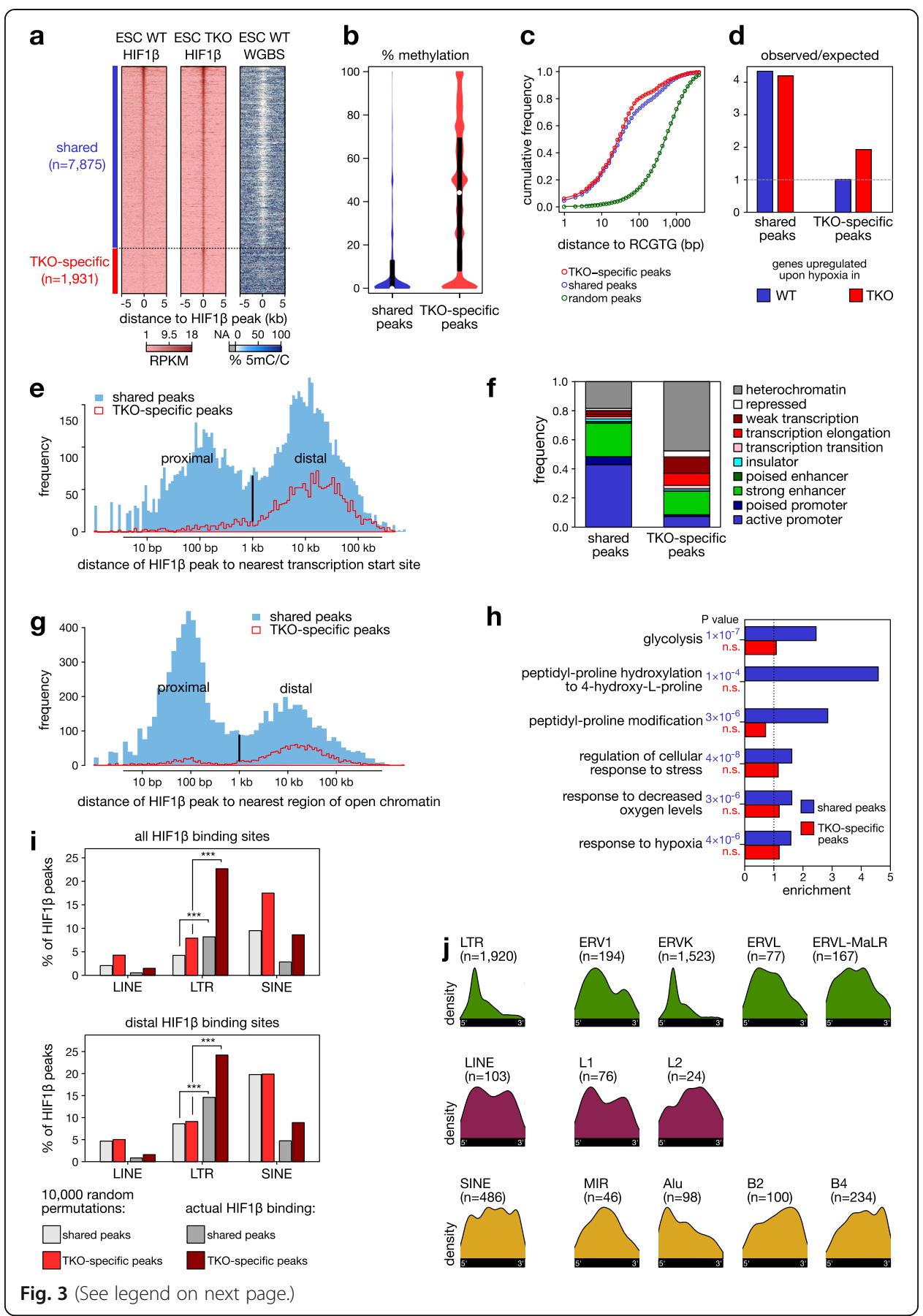


(See figure on previous page.)

Fig. 3 DNA demethylation uncovers new HIF1 $\beta$ binding sites. a Heatmaps of HIF1 $\beta$ binding (RPKM) and DNA methylation as determined using WGBS at regions flanking the summit of HIF1 $\beta$ binding peaks $( \pm 5$ $\mathrm{kb}$ ) either shared with WT or TKO-specific ESCs. b \% methylation at shared and TKO-specific HIF1 $\beta$ binding sites in WT ESCS. See Additional file 1: Fig. S5 for scatter plots illustrating the correlations between HIF1 $\beta$ ChIP-seq replicates in Dnmt-WT versus Dnmt-TKO ESCs. c Cumulative frequency of distance to the nearest RCGTG motif for shared, TKO-specific, and randomized HIF1 $\beta$ binding peaks. $\mathbf{d}$ Observed/expected frequency of upregulated genes associated with shared and TKO-specific HIF1 $\beta$ binding peaks in WT and Dnmt-TKO ESCs exposed to $24 \mathrm{~h}$ of hypoxia $\left(0.5 \% \mathrm{O}_{2}\right)$. e Distance of shared and TKO-specific HIF1 $\beta$ binding peaks in ESCs to the nearest TSS. A bimodal peak was detected indicating proximal and distal binding events. f Functional genome annotation using ChromHMM of shared and TKO-specific HIF1 $\beta$ binding peaks in ESCS. $\mathbf{g}$ Distance of shared and TKO-specific HIF1 $\beta$ binding peaks to open chromatin regions in ESCs. A bimodal peak was detected indicating proximal and distal binding events. $\mathbf{h}$ Ontology analysis of genes associated with shared and TKO-specific HIF1 $\beta$ binding peaks in ESCS. i HIF1 $\beta$ binding sites in LINES, LTRS, and SINEs after 10,000 random permutations and as observed by HIF1 $\beta$ ChIP-seq (actual HIF1 $\beta$ binding) for all HIF1 $\beta$ sites (top panel) and only for distal HIF1 $\beta$ sites (bottom panel). ${ }^{* * *} P<0.001$ by Fisher's exact test. $\mathbf{j}$ Distribution of HIF1 $\beta$ binding peaks detected in murine Dnmt-TKO ESCs for the retrotransposon families, color-coded by retrotransposon class (green: LTR; violet: LINE; yellow: SINE)

binding peaks were often distal to TSSs, and binding at LTRs was enriched over a randomization of HIF1 $\beta$ binding site positions (Fig. 4c). Notably, different retrotransposons were affected in human MCF7 cells compared to murine ESCs due to the evolutionarily divergent repeat content of these genomes. An analysis of the distribution of HIF1 $\beta$ binding peaks at retrotransposons, however, revealed that HIF1 $\beta$ binding sites were often at the $5^{\prime}$-end of retrotransposon sequences and that patterns of binding were conserved between mouse and human genomes (Fig. 3j versus Fig. 4d), suggesting that HIF binding on retrotransposons is not random but functional, inducing their expression.

To confirm the latter, we applied RNA-seq to assess changes in retrotransposon expression after $24 \mathrm{~h}$ of hypoxia with or without aza. Repeat expression was analyzed using different bioinformatics pipelines. First, we used RepEnrich [29], which combines repeatassociated reads, also those that are non-uniquely mapping, to assess repeat expression for each of the 779 retrotransposon subfamilies annotated in the human genome (these are each member of one of the 25 families that constitute the LTR, LINE, and SINE retrotransposon classes). We found that, already under hypoxia alone, 251 of all LTR (44\%), 51 of all LINE (32\%), and 5 of all SINE (10\%) subfamilies were upregulated, while only 16 LTR, 7 LINE, and no SINE subfamilies were downregulated (5\% FDR; Additional file 1: Fig. S6h-i). Next, we used SQuIRE, which assigns reads (including non-uniquely mapping reads) to a specific repeat locus based on an expectation-maximization algorithm [30]. With SQuIRE, 72\% ( $n=2781)$ of all differentially expressed repeat loci exhibited increased expression under hypoxia $\left(P<10^{-16}\right.$; Additional file 1: Fig. S6j).

\section{Induction of cryptic transcripts by hypoxia}

Hypoxia-induced transcripts were, however, often not matching the annotated repeat locus, but extending well beyond their annotated end, with some transcripts encompassing multiple repeat elements. Also, we noticed that for many transcripts, HIF1 $\beta$ binding did not occur in the retrotransposon promoter, while some other transcripts did even not contain a retrotransposon-associated sequence. Similar transcripts were also induced by aza. We therefore refer to these as "cryptic transcripts" (Additional file 1: Fig. S7a). To more accurately quantify them, we developed a novel analysis pipeline, 

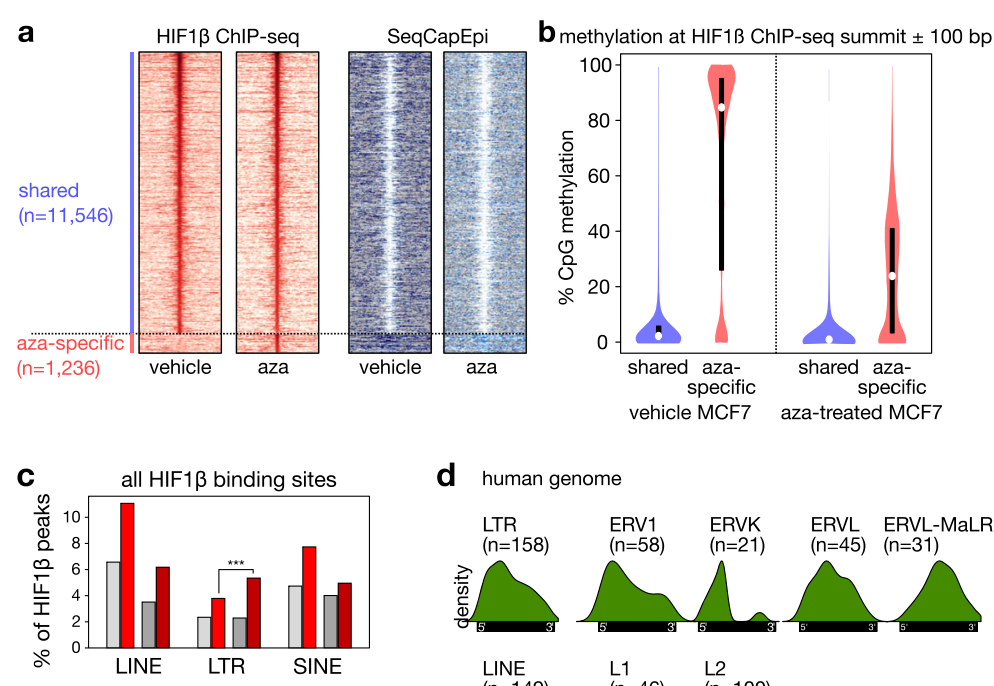

d human genome
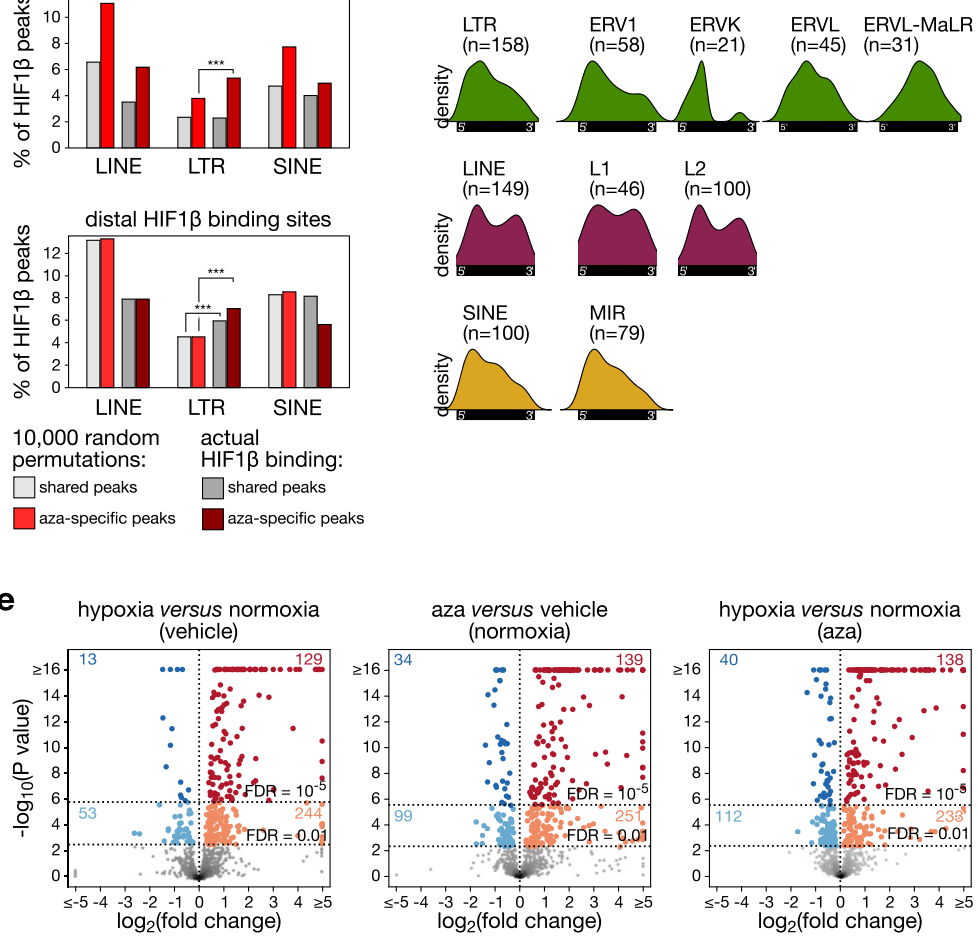

f

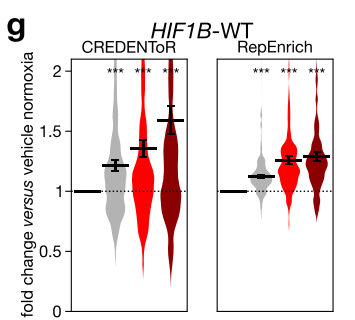

h
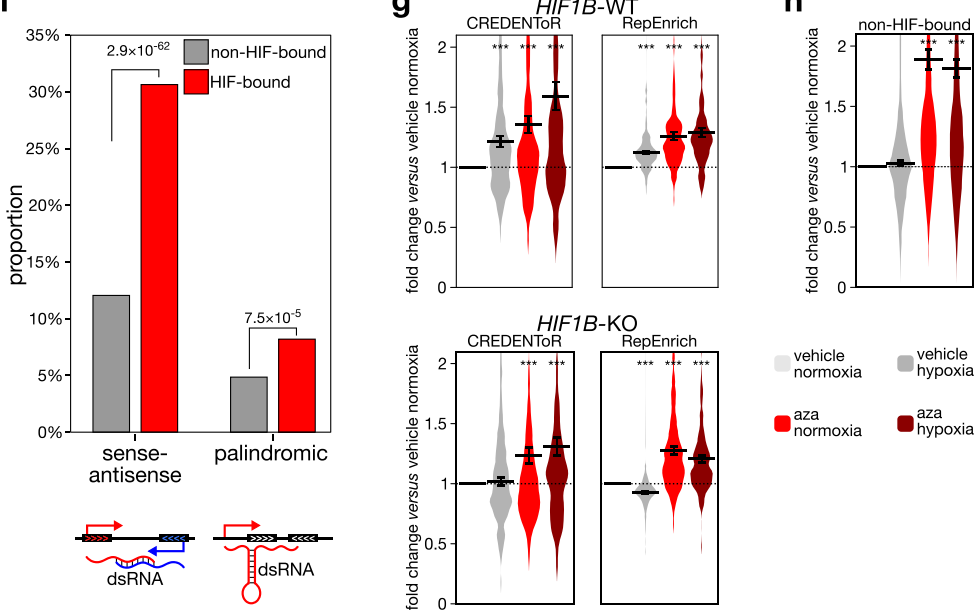

vehicle
normoxia $\boldsymbol{\bullet}_{\text {normoxia }}^{\text {aza }} \boldsymbol{\bullet}_{\text {hypoxia }}^{\text {aza }}$

Fig. 4 (See legend on next page.) 
(See figure on previous page.)

Fig. 4 DNA methylation represses hypoxia-induced cryptic transcript activation (a) Heatmaps of HIF1 $\beta$ binding (RPKM) and DNA methylation as determined using SeqCapEpi BS-seq at regions flanking the summit of HIF1 $\beta$ binding peaks ( $\pm 5 \mathrm{~kb}$ ). Shown are HIF1 $\beta$ binding peaks that are shared between vehicletreated and aza-treated MCF7 cells, or that are specific to aza-treated cells. In total, 12,782 HIF1 $\beta$ binding peak positions were detected across vehicle- and aza-treated MCF7 using a $P<10^{-15}$ threshold. $\mathbf{b}$ Violin plots of methylation detected by SeqCapEpi BS-seq at HIF1 $\beta$ binding peaks that are shared between vehicle-treated and aza-treated MCF7 cells, or that are specific to aza-treated MCF7 cells. c HIF1 $\beta$ binding sites in LINEs, LTRs, and SINEs after 10,000 random permutations and as observed by HIF1 $\beta$ ChIP-seq (actual HIF1 $\beta$ binding) for HIF1 $\beta$ binding peaks that are shared between vehicle- and aza-treated MCF7 cells, or specific to aza-treated MCF7 cells for all HIF1 $\beta$ sites (top panel) and only for distal HIF1 $\beta$ sites (bottom panel). d Distribution of HIF1 $\beta$ binding peaks detected in aza-treated MCF7 cells at retrotransposon families, colorcoded by retrotransposon class (green: LTR; violet: LINE; yellow: SINE). e Volcano plots showing differential expression of HIF-bound cryptic transcripts, as determined by CREDENToR in MCF7 cells exposed to vehicle (DMSO) or 5-aza-2'-deoxycytidine (aza; 1 MM) for 4 days, hypoxia (0.5\% oxygen, 1 day) or normoxia. Significantly upregulated and downregulated transcripts are highlighted in red and blue, respectively. The associated numbers refer to how many transcripts are up- or downregulated at a 1\% FDR and a $0.001 \%$ FDR, as indicated by the horizontal line. $\mathbf{f}$ dsRNA formation potential of all cryptic transcripts (gray) and of HIF-bound cryptic transcripts (red). Shown are the fraction of all RNAs for which transcription overlaps with a transcript expressed from the complementary strand ("sense-antisense"), and RNAs containing the same retrotransposon repeat element in sense and antisense orientation ("palindromic"). P values from the chisquare test. $\mathbf{g}, \mathbf{h}$ Expression of HIF-bound ( $\mathbf{g}$ ) and non-HIF-bound (h) cryptic transcripts relative to vehicletreated controls (vehicle normoxia) in MCF7 cells wild-type (WT) (g upper panels and $\mathbf{h}$ ) or knockout (KO) ( $\mathbf{g}$ bottom panels) for HIF1B. Shown are expression changes as assessed using CREDENTOR ( $\mathbf{g}$ left panels and $\mathbf{h}$ ) and RepEnrich (g right panels), with error bars indicating geometric mean \pm s.e.m. n.s. not significant, ${ }^{* * *} P<$ 0.001 by $t$-test

CRyptic Elements' Differential Expression by de Novo Transcriptome Reconstruction (CREDENToR). CREDENToR first performs a de novo transcriptome assembly to define cryptic transcripts and then assigns uniquely mapping reads to them to quantify their expression. The cryptic transcripts detected by CREDENToR are poorly conserved, often unspliced transcripts, shorter than lincRNAs but expressed at similar levels (see "Methods" and Additional file 1: Fig. S7b-g for benchmarking).

CREDENToR identified that out of 1389 differentially expressed cryptic transcripts (1\% FDR), 67\% were upregulated by hypoxia (Additional file 1: Fig. S6k). As expected, focusing on HIF-bound cryptic transcripts revealed an even stronger enrichment, with $82 \%$ and $91 \%$ (respectively, at $1 \%$ and $0.001 \%$ FDR) differentially expressed transcripts being upregulated following hypoxia (Fig. 4e). HIF binding was enriched at the promoter of hypoxia-induced cryptic transcripts, but far less in those induced by aza (Additional file 1: Fig. S6l). Interestingly, significant fractions of cryptic transcripts contained palindromic repeats, or overlapped with other transcripts in the reverse orientation, and could thus produce double-stranded (ds) RNA. HIF-bound cryptic transcripts were twice as likely to generate such dsRNAs (Fig. 4f). Together, this suggests HIF binding to leverage cryptic TSS structures within and outside the repeat genome to express dsRNA-generating cryptic transcripts.

Cryptic transcript expression was indeed dependent on HIF, as non-HIF-bound cryptic transcripts failed to show induction following hypoxia (Fig. 4g). To confirm this, we assessed expression in HIF1B-knockout MCF7 cells. Here, hypoxia failed to upregulate cryptic transcripts, according to both CREDENToR and RepEnrich (Fig. 4g, Additional file 1: Fig. S6m). As expected, aza-induced overexpression was retained, while hypoxia in HIF1B-knockout MCF7 cells failed to increase the effect of aza. Pharmacological activation of HIF using dimethyloxalylglycine (DMOG), a broad-spectrum inhibitor of 2oxoglutarate-dependent hydroxylases [31], affected cryptic transcripts similar to 
hypoxia (Additional file 1: Fig. S6m-o). Combined, these data indicate that hypoxia triggers HIF binding to unmethylated repeat regions, inducing HIF-dependent expression of cryptic transcripts, most of which are associated with retrotransposons.

\section{Hypoxia and repeat transcript expression affect tumor immunotolerance}

Expression of repeat transcripts has been linked to tumor foreignness [32], interferon (IFN) response [33-35], and enhanced cytolytic activity [36], all critical determinants of response to checkpoint immunotherapy. Similar to our own data, such transcripts were shown to increase dsRNA formation. This triggers IFN responses through viral mimicry. Cryptic transcripts induced by HIF could thus contribute to an immune-activated microenvironment.

To study this in more detail, we reanalyzed expression and DNA methylation data from The Cancer Genome Atlas (TCGA). We classified 5193 tumors from 14 tumor types as hypoxic or normoxic using an established hypoxia metagene expression signature [37]. We remapped all RNA-seq reads to determine expression of retrotransposon subfamilies using RepEnrich, and also performed de novo transcript assembly to identify on average 11,654 non-overlapping cryptic transcripts per tumor type using CREDENToR (Additional file 1: Fig. S8a). While TCGA tumors were not exposed to DNA demethylating agents, they did show variation in DNA methylation at TSS of cryptic transcripts. Indeed, although CpGs in cryptic transcript promoters showed mostly high methylation levels (median $=80.7 \%)$, there was considerable variability $(9.2 \%$ standard deviation), and one in 10 tumors displayed median levels below $67.3 \%$. Remarkably, and in line with our in vitro data, there was a significant interaction between hypoxia and DNA methylation in determining cryptic transcript expression $(P=0.0109)$, with expression being increased in hypoxic tumors having lower methylation at cryptic transcripts (Fig. 5a). At least 1279 cryptic transcripts showed increased expression of 10 -fold or higher $(\mathrm{FDR}<0.01$, Additional file 1: Fig. S8b). A reanalysis of combined single-cell methylome-and-transcriptome sequencing data from colorectal cancer cells [39] moreover confirmed that cryptic transcript expression and promoter methylation are inversely correlated, and this more strongly in hypoxic than normoxic cancer cells $(P=0.032$ in a general linear model), suggesting that the observed interactions are cancer cell-intrinsic (Additional file 4).

In TCGA, this interaction was only detected in tumor types known to respond to immunotherapy [38] ( $P=0.0031$ in $n=2505$ responsive tumors versus $P=0.69$ in $n=2681$ non-responsive tumors; see "Methods" for a detailed description of the generalized linear model; Fig. 5b, c). As expected, responsive tumor types exhibited an increased tumor mutation burden (TMB), elevated immune checkpoint expression, more $\mathrm{CD} 8^{+} \mathrm{T}$ cells, and increased cytolytic activity (Additional file 1: Fig. S8c) [40]. Importantly, responsive types also had on average lower methylation at cryptic transcripts and higher cryptic transcript expression than non-responsive types $\left(P<10^{-16}\right.$ for both comparisons, Fig. 5d). Single-cell RNA-seq analyses (both from 5' and 3' end) highlighted that cancer cells show the highest level of cryptic transcript expression compared to stromal cells, indicating they represent the main source of cryptic transcripts expression (Additional file 1: Fig. S8d). In line with our in vitro findings, DNA hypomethylation thus underlies cryptic transcript expression in hypoxic tumors, an effect that was particularly striking in immunotherapy-responsive tumors. 


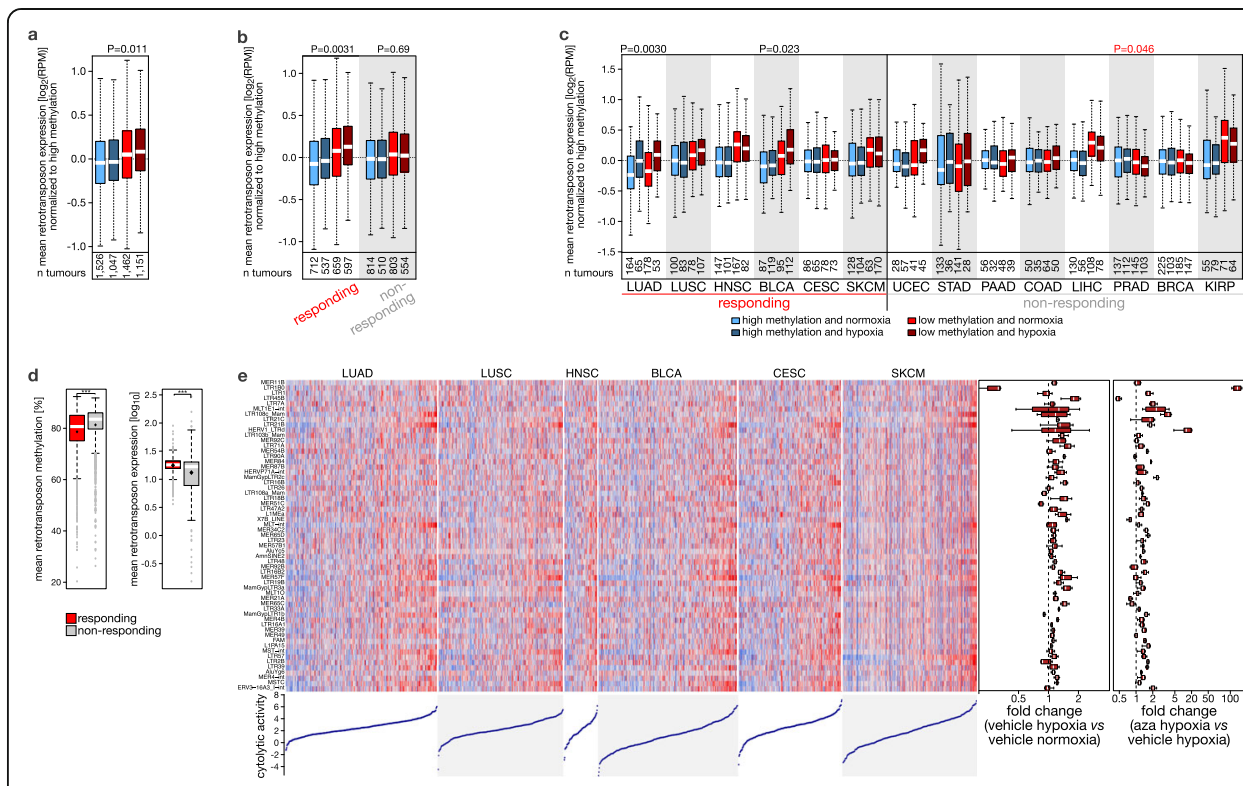

Fig. 5 Cryptic transcript expression in tumors. a-c Cryptic transcript expression in tumors characterized by TCGA. Shown is cryptic transcript expression in tumors with high or low methylation of cryptic transcript promoter regions (blue or red; > or $\leq$ the median methylation level of each tumor type), and in normoxic or hypoxic (light or dark color) tumors. Data are shown for a all tumor types combined, $\mathbf{b}$ stratified into those that are responding or non-responding to immunotherapy following the classification described by Turajlik and colleagues [38], and $\mathbf{c}$ for each tumor type separately. $P$ values by $t$-test, red values indicating inverse correlations. $\mathbf{d}$ DNA methylation levels at cryptic transcript promoters (left) and cryptic transcript expression (right) in tumors profiled in TCGA, stratified into tumor types that are responsive $(n=2280)$ or non-responsive $(n=2214)$ to checkpoint immunotherapy. ${ }^{* * *} P<0.001$ by $t$-test. e Heatmap showing the expression (Z-score, blue to red) of the 59 cryptic transcripts associated with cytolytic activity in tumors responsive to immunotherapy from TCGA. The boxplot on the right depicts the log fold change in expression of the same 59 cryptic transcripts in hypoxic versus normoxic MCF7 cells $\left(24 \mathrm{~h}, 0.5 \% \mathrm{O}_{2}\right)$, and of MCF7 cells after 4-day exposure to aza versus vehicle-treated hypoxic MCF7 cells ( $P<0.05$ for all cryptic transcripts, either for hypoxia versus vehicle, or for hypoxia plus aza versus aza alone). At the bottom, cytolytic activity of each TCGA sample is depicted. LUAD; lung adenocarcinoma; LUSC, lung squamous cell carcinoma; HNSC, head and neck squamous cell carcinoma; BLCA, bladder urothelial carcinoma; CESC, cervical squamous cell carcinoma and endocervical adenocarcinoma; SKCM, skin cutaneous melanoma

Overall, these observations support a model wherein hypoxia-induced cryptic transcripts are tolerated in high-immunogenic tumors, as these are characterized by high immune checkpoint expression, but not in low-immunogenic tumors where their expression would compromise tumor immunotolerance. This suggests that low-immunogenic tumors may need to maintain high DNA methylation levels in cryptic transcripts to downregulate their expression and avoid the induction of tumor immunogenicity.

\section{Aza compromises tumor immunotolerance in mice via HIF}

To confirm that in low-immunogenic tumors DNA methylation prohibits cryptic transcript expression, we identified 59 such retrotransposons that correlate in expression with cytolytic activity in immunotherapy-responsive tumor types within TCGA. Remarkably, all of these were upregulated in vitro, by hypoxia alone or hypoxia in combination with aza $(P<0.05$, Fig. 5e), suggesting that hypoxia and DNA demethylation can indeed enhance tumor immunogenicity. To confirm this experimentally, we screened several mouse tumor models for their immunogenicity. The orthotopic 4T1 
breast cancer model was identified as low-immunogenic. Indeed, 4T1 tumors exhibited a low $\mathrm{TMB}$, cytolytic activity, number of $\mathrm{CD}^{+} \mathrm{T}$ cells and expression of immune checkpoints $(P d 1, P d l 1)$ compared to other models (Additional file 1: Fig. S9a). In line with 4T1 grafts being low-immunogenic tumors, anti-PD1 treatment failed to affect their growth $(-8 \%, P=0.397)$, while significantly reducing growth of highimmunogenic tumors, as described previously [41, 42] (Additional file 1: Fig. S9b). Importantly, also the expression of cryptic transcripts was lower in 4T1 than in highimmunogenic tumor models (Additional file 1: Fig. S9c).

Next, we verified in low-immunogenic 4T1 cells whether DNA demethylation upregulates cryptic transcripts in a HIF-dependent manner. In vitro, we observed that, similar to MCF7 cells, both hypoxia and aza independently increased cryptic transcript expression, both using CREDENToR and RepEnrich (Fig. 6a; Additional file 1: Fig. S9d). Likewise, aza increased cryptic transcript expression in vivo (Fig. 6b). To confirm that this upregulation was at least partially hypoxia-mediated, we investigated whether tumor hypoxia enhances aza-induced cryptic transcript expression. We compared azatreated 4T1 tumor-bearing mice injected either with control or anti-VEGFR-2 antibody (DC101). While vehicle-treated 4T1 tumors were hypoxic in $\sim 40 \%$ of the tumor, DC101 further reduced blood vessel density $(-35 \% ; P<0.05)$ and increased hypoxic tumor areas (68\%; $P<0.05$; Fig. 6c, d). Importantly, this was associated with an increase in cryptic transcripts $\left(+9 \% ; P=2.6 \times 10^{-16}\right.$; Fig. 6 e).

We then explored whether this increase also compromised immunotolerance. As immunogenicity of cryptic transcripts is mediated via dsRNA formation, we first confirmed in vitro by immunostaining the increase in dsRNA after both hypoxia and aza in 4T1 cells (Fig. 6f). In vivo, aza reduced growth of $4 \mathrm{~T} 1$ tumors $\left(-32 \% ; P=3.0 \times 10^{-3}\right.$; Fig. 6 g), but did not reduce cell proliferation marker expression (Additional file 1: Fig. S9e). In contrast, immune activation was enhanced in tumors treated with aza, as activated $\mathrm{T}$ cell and natural killer cell signatures were upregulated and myeloid-derived suppressor cell signatures downregulated (Fig. 6h). Immunofluorescence of $\mathrm{CD}^{+} \mathrm{T}$ cells confirmed these changes: while $\mathrm{T}$ cell infiltration was unaffected, the number of activated, granzyme Bpositive $\mathrm{T}$ cells increased 2.1-fold ( $P<0.05$; Additional file 1: Fig. S9f).

To verify HIF-dependence of these immunogenic effects, we generated polyclonal $4 \mathrm{~T} 1$ cells deficient for HIF1 $\beta$ by CRISPR-Cas9 (4T1 ${ }^{\text {Hiflb-KO}}$; Additional file 1: Fig. S9g) and compared these cells to scramble-control $4 \mathrm{~T} 1$ cells $\left(4 \mathrm{~T} 1^{\text {Hif } 1 b \text {-scr }}\right)$, while treating with aza or vehicle. In vitro, loss of HIF1 $\beta$ abrogated hypoxia-induced dsRNA formation and HIF1 $\beta$-bound cryptic transcript expression both in vehicle and aza-treated cells (Additional file 1: Fig. S9d and h), similar to what we observed in MCF7 cells. Also in vivo, $4 \mathrm{~T} 1^{\text {Hiflb-KO }}$ showed reduced cryptic transcript expression compared to $4 \mathrm{~T} 1^{\text {Hifl } 1 \text {-scr }}$ grafts, effects that were limited to HIF-bound cryptic transcripts as expected (Fig. 6i; Additional file 1: Fig. S9i). Of note, $4 \mathrm{~T} 1^{\text {Hiflb-KO }}$ tumors grew much more slowly than $4 \mathrm{~T} 1^{\text {Hiflb-scr }}$ tumors, presumably because HIF1 $\beta$ also has direct effects on cell proliferation, thus rendering it challenging to disentangle effects on immunogenicity. Nevertheless, aza induced a similar and significant upregulation of cancer testis antigen expression in both cell lines (Additional file 1: Fig. S2), suggesting similar treatment efficacy. Interestingly, while $4 \mathrm{~T} 1^{\text {Hiflb-scr }}$ grafts also showed a significantly reduced size when comparing aza to vehicle ( $46 \%$ reduction; $\left.P=3.3 \times 10^{-6}\right)$, $4 \mathrm{~T}^{\text {Hifl } b \text {-KO }}$ failed to show as strong a reduction (only $22 \% ; P=7.0 \times 10^{-4}$, or 1.8 -fold less than the scramble 


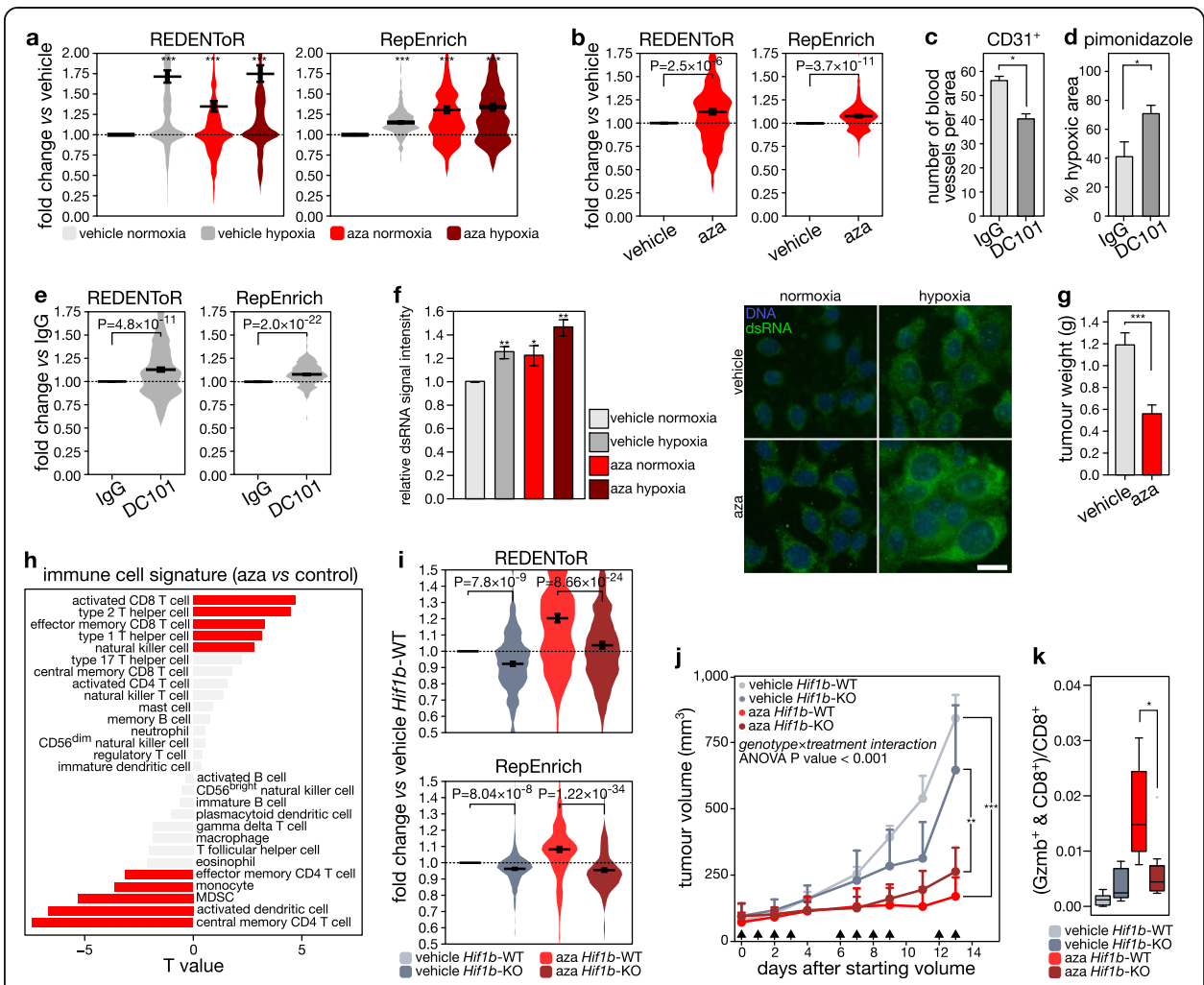

Fig. 6 Aza treatment increases tumor immunogenicity HIF-dependently. a Expression in 4T1 cells of cryptic transcripts (CREDENToR, left) or retrotransposon subfamilies (RepEnrich, right) bound by HIF1 $\beta$ in hypoxic 4T1 cells, following exposure to vehicle (DMSO) or 5-aza-2'-deoxycytidine (aza; $1 \mu \mathrm{M})$ for 4 days, hypoxia (0.5\% oxygen, 1 day) or normoxia. Difference in the distribution of expression is expressed as fold change of counts per million over control $4 \mathrm{~T} 1$ cells. Error bars indicate geometric mean \pm s.e.m. $\mathbf{b}$ Expression of cryptic transcripts (CREDENToR, left) or retrotransposon subfamilies (RepEnrich, right) bound by HIF1 $\beta$ in $4 \mathrm{~T} 1$ cells in vehicle- and aza-treated 4T1 tumors ( $n=6$ per treatment condition). Difference in the distribution of expression is expressed as fold change of counts per million over control 4T1 tumors. Error bars indicate geometric mean \pm s.e.m. c, d Quantification of the number of blood vessels (CD31 staining; $\mathbf{c}$ ) and percentage of hypoxia (pimonidazole staining; $\mathbf{d}$ ) in 4T1 tumors from mice injected with DC101 or control lgG (with at least 4 mice per treatment condition, see "Methods"). e Expression of cryptic transcripts and retrotransposon subfamilies (bound by HIF1 $\beta$ in $4 \mathrm{~T} 1$ cells) as determined by CREDENTOR (left) and RepEnrich (right) in control antibody- and DC101-treated 4T1 tumors ( $n=6$ per treatment condition). Difference in the distribution of expression is expressed as fold change of counts per million over control 4T1 tumors. Error bars indicate geometric mean \pm s.e.m. $\mathbf{f}(\mathrm{left})$ Signal intensity of dsRNA staining in 4T1 cells treated with aza or PBS and incubated in hypoxia or normoxia for $24 \mathrm{~h}$. (right) Immunofluorescence of dsRNA using a dsRNA antibody (clone J2, green) in $4 \mathrm{~T} 1$ cells treated with aza or vehicle (PBS), and by a 24-h incubation in hypoxic $\left(0.5 \% \mathrm{O}_{2}\right)$ or normoxic conditions (scale $\left.40 \mu \mathrm{m}\right)$. A representative image is shown for each condition. $\mathbf{g}$ Barplot showing the tumor weight of vehicle- and aza-treated $4 \mathrm{~T} 1$ tumors ( $n=6$ per treatment condition). ${ }^{* * *} p<$ 0.001 by paired $t$-test. $\mathbf{h}$ Association between aza treatment and immune cell infiltration estimates in 4T1 tumors from mice treated with either aza or PBS, as calculated by GSVA on PanCancer immune metagenes [43] and visualized by their $T$ value (at least 6 mice per treatment condition were sequenced). Red bars indicate significant associations $(P<0.05)$. i Expression of cryptic transcripts (CREDENToR, top) and retrotransposon subfamilies (RepEnrich, bottom) bound by HIF1 $\beta$ in 4T1 cells in 4T1 tumors WT or KO for Hif1b implanted in mice treated with vehicle or aza (see "Methods," at least 6 tumors per treatment condition were sequenced). Difference in the distribution of expression is expressed as fold change of counts per million over Hif1b-WT vehicle-treated 4T1 tumors. Error bars indicate geometric mean \pm s.e.m. $\mathbf{j}$ Growth of tumors generated by grafting mice orthotopically

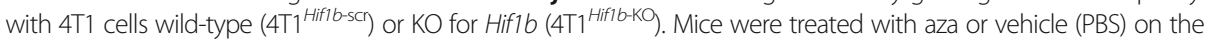
days indicated with an arrow (see "Methods"). Data represent mean and s.e.m. from independent experiments each with at least $n=6$ mice per group. ${ }^{*} P<0.05$ by $t$-test. A genotype-by-treatment interaction as assessed by ANOVA was $P<0.001$. $\mathbf{k}$ Quantification of $\mathrm{CD}^{+}$and granzyme $b(\mathrm{Gzmb})^{+}$cells, depicted as percentage of $\mathrm{CD} 8^{+}$

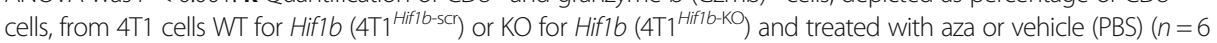
per group; see "Methods"). ${ }^{*} P<0.05$ by t-test 
effect; $P=0.021$; Fig. 6 j). The differential effect of aza in $4 \mathrm{~T} 1^{H i f l b-\mathrm{KO}}$ versus $4 \mathrm{~T} 1^{H i f 1 b \text {-scr }}$ grafts was also highly significant in an interaction analysis $(P<0.0001)$. Moreover, while the number of activated $\mathrm{T}$ cells increased in $4 \mathrm{~T} 1^{\text {Hiflb-scr }}$ grafts following aza, $4 \mathrm{~T} 1^{H i f 1 b-\mathrm{KO}}$ grafts failed to show such increase (Fig. 6k). This differential effect of aza, depending on the Hif1b background, was similarly significant in an interaction analysis $\left(P=6.3 \times 10^{-3}\right)$. Together, these data provide a mechanistic link between HIF1 $\beta$ binding, DNA methylation, and immune activation, highlighting the potential of DNA methylation inhibitors to activate the immune system and render immune-cold tumors immune-hot.

\section{Discussion}

Here, we show that DNA methylation directly repels binding of HIF transcription factors and that cell-type-specific DNA methylation patterns established under normoxic conditions underlie the differential hypoxic response between cell types. Furthermore, ectopic HIF binding sites in repeat elements are normally masked by DNA methylation but become accessible to HIF upon DNA demethylation, leading to expression of cryptic transcripts which enhance tumor immunogenicity.

Our findings are important for a number of reasons. Firstly, an instructive role of DNA methylation in gene expression regulation, as originally proposed by Holliday and Pugh and by Riggs [44, 45], has remained controversial. Indeed, in many instances it is unclear whether DNA methylation changes are a direct or indirect cause, or rather a consequence of TF binding or gene expression [2]. Our findings in murine and human both differentiated and undifferentiated cells align well with a recent study showing methylation dependence of NRF1 binding in mESCs. By demonstrating that DNA methylation directly repels HIF binding, we thus highlight the importance of DNA methylation profiling, especially in poorly oxygenated tissues. Since tumor hypoxia has long been associated with increased malignancy, poor prognosis, and resistance to radio- and chemotherapy [6], DNA methylation could especially provide insights in the processes underlying therapeutic resistance. For instance, Vanharanta and colleagues recently showed an association between DNA methylation near CYTIP and the survival of disseminating cancer cells [46]. Combined with our observations that DNA methylation directly repels HIF binding, this suggests remethylation of the CYTIP promoter as a viable avenue for decreasing cancer dissemination.

Secondly, it has been challenging to identify a guiding principle as to why specific genes are induced upon hypoxia in one, but not the other cell type [10]. Our findings suggest that cell-type-specific TF binding under normoxia causes differences in DNA methylation, which subsequently determine HIF binding under hypoxia and predict the cell-type-specific hypoxia response. We note that we did not model chronic but only acute hypoxia in vitro, conditions that do not directly alter DNA methylation and that are thus distinct from the prolonged, chronic hypoxia we previously described to be essential to cause DNA hypermethylation at promoters and enhancers by TET inhibition [1]. Importantly, we also confirmed earlier observations that HIF1 $\beta$ binding peaks are characterized by an active, open chromatin structure [12]. This additional requirement for functional HIF1 $\beta$ binding peaks probably explains why each of the RCGTG consensus sequences in the genome cannot serve as an equal HIF binding substrate in normal cells, or upon genetic or pharmacological demethylation. Similar observations were made for other TFs, such as CTCF, for which binding was similarly limited to sites 
containing a permissive chromatin structure [15, 24]. Importantly, binding specificities for HIF1 $\alpha$ versus HIF2 $\alpha$ are independent of DNA methylation, but appear to be influenced by chromatin context. This is in line with the identical structure of DNA binding domains of HIF1 $\alpha$ and HIF2 $\alpha$; swapping DNA binding domains between both proteins has no influence on their binding profile [47]. Instead, the transactivation domain appears to endow specificity, suggesting that accessory chromatin binding partners govern the differential binding of HIF $1 \alpha$ and HIF2 $\alpha$ [47].

Thirdly, several publications by now reported how 5-aza-2'-deoxycytidine initiates cryptic TSSs in the repeat genome, leading to expression of cryptic transcripts [33, 48]. Our data add to these findings by demonstrating that cryptic transcript expression is at least partly HIF-dependent, while more importantly, hypoxia alone is also capable of inducing their expression. Based on single-cell analyses, we observed this effect to be cancer cell-autonomous, consistent with cancer cells being hypomethylated. Our findings reinforce a growing body of evidence that highlights how during evolution transposable elements have copied and amplified regulatory regions throughout the genome [17, 49-53]. Most likely, transposable elements hijacked the transcriptional apparatus of their host to support their germline propagation [54]. In doing so, they copied the associated TF binding site and seeded it at the site of insertion. Transposable elements having binding sites for TFs that are active in the germline, are more likely to hijack these and transpose. Accordingly, HIF is activated in early development, when DNA methylation levels are also low [53, 55]; ancestral cooption of HIF binding sites by cryptic transcripts to increase their expression is thus plausible. In line with specific TFs preferentially acting on particular retrotransposon subfamilies, we observe enrichment of HIF binding and activation at LTRs, particularly at the LTR of ERVKs.

Finally, we uncover an intriguing opportunity for cancer immunotherapy. Chiapinelli et al. already demonstrated that aza-induced cryptic transcripts are highly immunogenic and can sensitize tumors to checkpoint immunotherapy [33], while Sheng et al. showed that also histone demethylase LSD1-ablation increases cryptic transcripts, thereby enabling checkpoint blockade [56]. The mechanism underlying immunogenicity likely depends on the formation of dsRNA, which via a viral mimicry-mediated process activates the immune system $[35,48,56]$. In addition, some of these transcripts contain open-reading frames, which could translate into abnormal proteins that can be antigenic [48]. Importantly, hypoxia is endemic to most solid tumors, and therefore could have a more widespread impact than aza. Indeed, in hypoxic tumors with high checkpoint expression, DNA methylation at TSS of cryptic transcripts was reduced and consequently, cryptic transcript expression increased. Since tumors with high checkpoint expression often respond to checkpoint immunotherapy, and as cryptic transcripts could sensitize tumors to checkpoint blockade [33,35], this suggests hypoxia-induced cryptic transcripts to play an important role in mediating the therapeutic effects exerted by checkpoint inhibitors. In contrast, immune-cold tumors characterized by low immune checkpoint expression were much less tolerant to cryptic transcript expression, showing high methylation at retrotransposon promoters. In light of our findings that methylation directly repels HIF binding, this suggests DNA methylation to block hypoxia-induced cryptic transcript expression in immune-cold tumors to maintain immunotolerance. Pharmacological demethylation of immune-cold 4T1 tumors indeed increased cryptic transcription, enhanced immunogenicity, and reduced tumor growth 
in a HIF-dependent manner. By showing that low-immunogenic, hypoxic tumors can be rendered immunogenic through DNA methylation inhibitors, we thus highlight a novel treatment strategy for tumors otherwise refractory to immunotherapies.

\section{Methods}

Materials

All materials were molecular biology grade. Unless noted otherwise, all were from Sigma (Diegem, Belgium).

\section{Cell lines}

MCF7, RCC4, SK-MEL-28, A549, 4T1, MC38, and CT26 cell lines were obtained from the American Type Culture Collection, and their identity was not further authenticated. None of these cell lines are listed in the database of commonly misidentified cell lines maintained by ICLAC. MCF7 HIF1B-knockout cells were previously described [20]. MCF7, RCC4, A549, MC38, and 4T1 cells were cultured at $37^{\circ} \mathrm{C}$ in Dulbecco's modified Eagle's medium (DMEM) with 10\% fetal bovine serum (FBS), $5 \mathrm{~mL}$ of $100 \mathrm{U} / \mathrm{mL}$ Penicillin-Streptomycin (Pen-Strep, Life Technologies), and $5 \mathrm{~mL}$ of L-glutamine 200 mM. SK-MEL-28 and CT26 cell lines were cultured at $37{ }^{\circ} \mathrm{C}$ in Roswell Park Memorial Institute 1640 Medium (RPMI) with 10\% FBS 1\% Pen-Strep and 1\% L-glutamine.

Murine embryonic stem cells (mESCs) that were triple-knockout for Dnmt1, Dnmt3a, and Dnmt3b (Dnmt-TKO) and triple-knockout for Tet1, Tet2, and Tet3 (Tet-TKO) and their appropriate wild-type (WT) control mESCs were obtained from Dr. Masaki Okano and Dr. Guoliang Xu respectively [57, 58]. mESCs that were knockout for Hif1b (Hiflb-KO) and their WT control mESCs were previously described [21]. Dnmt-TKO, Tet-TKO, Tet-WT, Hiflb-WT, and Hiflb-KO mESCs were cultured feeder-free in fibroblast-conditioned medium (DMEM with $4500 \mathrm{mg} / \mathrm{L}$ glucose, $2 \mathrm{mM}$ L-glutamine, 1 $\mathrm{mM}$ sodium pyruvate, $15 \%$ FBS, $1 \%$ Pen-Strep, $0.1 \mathrm{mM}$ of non-essential amino acids, $0.1 \mathrm{mM} \beta$-mercaptoethanol) on $0.1 \%$ gelatine-coated plates. mESCs from the 159 background used for the recombinase-mediated cassette exchange reaction were kindly provided by Prof. Dirk Schubeler (Friedrich Miescher Institute for Biomedical Research, Basel, Switzerland) and grown in ESC medium (DMEM with $4500 \mathrm{mg} / \mathrm{L}$ glucose, $2 \mathrm{mM}$ L-glutamine, $1 \mathrm{mM}$ sodium pyruvate, 15\% FBS, $1 \%$ Pen-Strep, $0.1 \mathrm{mM}$ of non-essential amino acids, $0.1 \mathrm{mM}$-mercaptoethanol, $10^{3} \mathrm{U}$ LIF ESGRO (Millipore)) containing $25 \mu \mathrm{g} / \mathrm{mL}$ hygromycin ( $50 \mu \mathrm{l}$ of $5 \mathrm{mg} / \mathrm{mL}$ stock per $10 \mathrm{~mL}$ medium) for at least 10 days. 4T1 cells that were knockout for Hif1b (Hif1b-KO) and their WT control cells were cultured at $37^{\circ} \mathrm{C}$ in DMEM with $10 \%$ FBS, $5 \mathrm{~mL}$ of $100 \mathrm{U} / \mathrm{mL}$ Pen-Strep, $10 \mu \mathrm{g} / \mathrm{mL}$ of blasticidin (ant-bl-05, Invivogen), puromycin (P9620, Sigma-Aldrich) $1.5 \mu \mathrm{g} / \mathrm{mL}$ medium, and $5 \mathrm{~mL}$ of L-glutamine $200 \mathrm{mM}$.

All cell cultures were confirmed to be mycoplasma-free every month.

\section{Cell line treatment conditions}

Cell cultures were grown under atmospheric $(21 \%)$ oxygen concentrations in the presence of $5 \% \mathrm{CO}_{2}$, or rendered hypoxic by incubating them under $0.5 \%$ oxygen $\left(5 \% \mathrm{CO}_{2}\right.$ and $94.5 \% \mathrm{~N}_{2}$ ). For ChIP-seq experiments, hypoxia was induced during $16 \mathrm{~h}$, whereas $24 \mathrm{~h}$ of exposure were used when assessing effects of hypoxia on gene or protein 
expression level. Where indicated, cells were pre-treated with 5-aza-2'-deoxycytidine (aza, $1 \mu \mathrm{M})$ for 3 days by adding the required volume to fresh culture medium. Equal volumes of the carrier (DMSO) were used as control. This was followed by another day of exposure to aza in hypoxia or normoxia, bringing the total aza exposure time for experiments to 4 days. Then, $2 \mathrm{mM}$ of DMOG (dimethyloxalylglycine, Sigma) was added to culture medium for $24 \mathrm{~h}$ where indicated. Cytotoxicity was tested using sulforhodamine B assays as described [59]. Cells were always plated at a density tailored to reach $80-95 \%$ confluence at the end of the treatment. Fresh medium was added to the cells just prior to hypoxia. To prove that the extent to which cells were exposed to hypoxia was similar across experiments, we assessed that induction of hypoxia marker genes (BNIP3, EGLN, ALDOA, $C A 9)$ but not HIF1A occurred in each experiment (Additional file 1: Fig. S2). For experiments involving exposure to aza, we assessed the expression of cancer testis antigens as a positive control (Additional file 1: Fig. S2).

\section{LC-ESI-MS/MS of DNA to measure $5 \mathrm{mC}$}

DNA was extracted and processed for LC-ESI-MS/MS to determine $5 \mathrm{mC}$ concentrations exactly as described previously [1].

\section{Western blot}

To assess HIF1 $\alpha$ protein stabilization, proteins were extracted from cultured cells as follows: cells were placed on ice, washed twice with ice-cold PBS, and lysed in protein extraction buffer $(50 \mathrm{mM}$ Tris- $\mathrm{HCl}, 150 \mathrm{mM} \mathrm{NaCl}, 1 \%$ Triton X-100, 0.5\% Na-deoxycholate, $0.1 \%$ SDS, and $1 \times$ protease inhibitor cocktail (Roche)). Protein concentrations were determined using a bicinchoninic acid protein assay (BCA, Thermo Scientific) following the manufacturer's protocol. An estimated $60 \mu \mathrm{g}$ of protein was loaded per well on a NuPAGE Novex 3-8\% Tris-Acetate Protein gel (Life Technologies), separated by electrophoresis and blotted on polyvinylidene fluoride membranes. Membranes were activated with methanol and washed with Tris-buffered saline (TBS; $50 \mathrm{mM}$ Tris- $\mathrm{HCl}, 150 \mathrm{mM} \mathrm{NaCl}$ ) with $0.1 \%$ Tween 20 , and incubated with rabbit $\alpha$-tubulin (2144S, Cell Signaling), rabbit $\beta$-actin (4967, Cell Signaling), rabbit HIF-1 $\beta /$ ARNT (D28F3) XP (5537, Cell Signaling) at 1:1000 dilution, and rabbit HIF-1 $\alpha$ (C-Term) Polyclonal Antibody (Cayman Chemical Item 10006421) 1:3000. Incubation with the secondary antibodies and detection were performed according to routine laboratory practices. Western blotting was done on 3 independent biological replicates.

\section{Analysis of HIF1 $\beta$ target genes using ChIP-seq}

$20-25 \times 10^{6}$ cells were incubated in hypoxic conditions for $16 \mathrm{~h}$. Cultured cells were subsequently immediately fixed by adding $1 \%$ formaldehyde ( $16 \%$ formaldehyde $(\mathrm{w} / \mathrm{v})$, methanol-free, Thermo Scientific) directly in the medium and incubating for $8 \mathrm{~min}$ on a flat-bed shaker at room temperature (RT). Fixed cells were incubated with $150 \mathrm{mM}$ of glycine for $5 \mathrm{~min}$ to revert the cross-links, washed twice with ice-cold PBS $0.5 \%$ Triton-X100, scraped, and collected by centrifugation $\left(1000 \times g, 5 \mathrm{~min}\right.$ at $\left.4{ }^{\circ} \mathrm{C}\right)$. The pellet was resuspended in $1400 \mu \mathrm{L}$ of RIPA buffer $(50 \mathrm{mM}$ Tris- $\mathrm{HCl} \mathrm{pH} 8,150 \mathrm{mM} \mathrm{NaCl}$, 2 mM EDTA pH 8, 1\% Triton-X100, 0.5\% Sodium deoxycholate, 1\% SDS, 1\% protease inhibitor) and transferred to a new Eppendorf tube. The lysate was homogenized by passing through an insulin syringe and incubated on ice for $10 \mathrm{~min}$. The chromatin was 
sonicated for 3 min by using a Branson 250 Digital Sonifier with $0.7 \mathrm{~s}$ "On" and $1.3 \mathrm{~s}$ "Off" pulses at $40 \%$ power amplitude, yielding predominantly fragment sizes between 100 and 500 bps. The sample was kept ice-cold at all times during the sonication. Next, samples were centrifuged $\left(10 \mathrm{~min}\right.$ at $16,000 \times \mathrm{G}$ at $\left.4{ }^{\circ} \mathrm{C}\right)$ and supernatant transferred in a new Eppendorf tube. Protein concentration was assessed using a BCA. A total of $50 \mu \mathrm{L}$ of sheared chromatin was used as "input," and $1.4 \mu \mathrm{g}$ of primary ARNT/HIF1 $\beta$ monoclonal antibody (NB100C124, Novus) per $1 \mathrm{mg}$ of protein was added to the remainder of the chromatin and incubated overnight at $4{ }^{\circ} \mathrm{C}$ in a rotator. Next, Pierce Protein A/G Magnetic Beads (Life Technologies) were added to the samples in a volume that is $4 \times$ the volume of the primary antibody and incubated at $4{ }^{\circ} \mathrm{C}$ for at least $5 \mathrm{~h}$. A/G Magnetic Beads were collected and washed 5 times with washing buffer $(50 \mathrm{mM}$ Tris- $\mathrm{HCl}, 200 \mathrm{mM} \mathrm{LiCl}$, 2 mM EDTA, pH 8, $1 \%$ Triton, $0.5 \%$ sodium deoxycholate, $0.1 \%$ SDS, $1 \%$ protease inhibitor), and twice with TE buffer. The A/G magnetic beads were resuspended in $50 \mu \mathrm{L}$ of TE buffer, and $1.5 \mu \mathrm{L}$ of RNAse A (200 units, NEB, Ipswich, MA, USA) was added to the A/G beads samples and to the input, incubated for $30 \mathrm{~min}$ at $37^{\circ} \mathrm{C}$. After addition of $1.5 \mu \mathrm{L}$ of Proteinase K (200 units, NEB) and overnight incubation at $65^{\circ} \mathrm{C}$ on a stirrer, the beads were removed from the solution using a magnet and DNA was purified using $1.8 \times$ volume of Agencourt AMPure XP (Beckman Coulter) according to the manufacturer's instructions. DNA was eluted in $20 \mu \mathrm{L}$ of TE buffer. The input DNA was quantified on NanoDrop. Next, $1 \mu \mathrm{g}$ of the input and all the immunoprecipitated DNA was converted into sequencing libraries using the NEBNext DNA library prep master mix set (NEB) following manufacturer's instructions.

A single end of these libraries was sequenced for 50 bases on a HiSeq, either HiSeq2500 or HiSeq4000 (Illumina), mapped using Bowtie and extended for the average insert size (250 bases). ChIP peaks were called by Model-based Analysis for ChIP-Seq (MACS) [16], with standard settings and using read counts from an input sample as baseline.

HIF1 $\beta$ binding peak positions in the human cell lines MCF7 (both vehicle- and azatreated), RCC4, A549, and SK-MEL-28 were defined by using the stringent threshold $P<10^{-15}$. A threshold equal to $P<10^{-10}$ was used to define HIF1 $\beta$ binding peaks in murine cell lines (4T1, Dnmt-WT, and Dnmt-TKO ESCs).

To compare HIF1 $\beta$ binding peaks between human cell lines (MCF7, RCC4, A549, and SK-MEL-28), HIF1 $\beta$ binding peaks were called as present if the average coverage at the 200 bps centered on the summit was $>4$-fold bigger than the local background, and as absent if it was $<2.5$-fold smaller than the local background, with local background being defined as the read depth across regions $1.5-5 \mathrm{~kb}$ up- and downstream of the peak. Intermediate coverage was annotated as unclassified. To compare HIF1 $\beta$ binding peaks between murine Dnmt-WT and Dnmt-TKO ESCs, the HIF1 $\beta$ binding peak was called as present if the average coverage at the 200 bps centered on the summit was $>4$-fold bigger than the background, and as absent if it was $<4$-fold smaller than the background. To compare efficiency between experiments, scatter plots of read counts at peak regions of HIF1 $\beta$ binding regions were generated per cell line in a pairwise fashion.

\section{Annotation of genomic features}

Human sequences were mapped to genome build hg19 and murine sequences to genome build mm10. Putative HIF binding sites were detected genome-wide by screening 
the whole genome for RCGTG motifs using the regular expression search tool dreg (www.bioinformatics.nl/cgi-bin/emboss/help/dreg). The frequency per bp of RCGTG motifs inside HIF1 $\beta$ binding peaks and in the rest of the genome was calculated, and enrichment of RCGTG motifs at HIF1 $\beta$ binding peaks quantified by overlapping RCGTG positions in the genome with the HIF1 $\beta$ binding peak positions as defined by MACS.

The distances of HIF1 $\beta$ peaks to the nearest RCGTG motif (cumulative frequency), TSS, and open chromatin (frequency) were calculated by overlapping each genomic feature with HIF1 $\beta$ peak positions using BedTools in R. Protein-coding genes were annotated as per Ensembl version 92. Promoter regions were annotated as being $2 \mathrm{~kb}$ upstream or $500 \mathrm{bp}$ downstream of the start site of each gene. Chromatin state annotation of MCF7 and mESCs was as described [23, 60]. HIF1 $\beta$ binding peaks were annotated with these features and overlapped with the repeat genome using BedTools. To assess enrichment of HIF binding at repeats, HIF1 $\beta$ binding peaks were 10,000 times either randomly distributed throughout the genome, or randomly distributed while matching the distal binding peak distribution. Next, the frequency of repeat binding in a random distribution was compared to that in the observed distribution. Peaks randomly assigned to poorly mapping regions were discarded.

\section{Genome distribution of 5mC: BS-seq, SeqCapEpi BS-seq and mDIP-seq}

BS-seq, SeqCapEpi BS-seq, and mDIP-seq were performed as described previously [1]. To quantify DNA methylation inside HIF1 $\beta$ binding peaks, SeqCapEpi probes with > $40 \times$ coverage were overlapped with HIF $1 \beta$ binding peaks as defined by MACS. Methylation levels at the probes overlapping and non-overlapping (rest of the genome) HIF1 $\beta$ binding peaks were calculated using Seqmonk.

ChIP-BS-seq was done as ChIP-seq, except that methylated adaptors (NEB) were ligated, and DNA libraries were bisulfite-converted using the EZ DNA MethylationLightning $^{\text {mi }}$ kit (Zymo) prior to library amplification using HiFi Uracil+ (KAPA). Reads were mapped using Bismark as described [1].

\section{RNA-seq}

To assess the impact of HIF binding at gene promoters on their expression, strandspecific RNA-seq was performed in human cell lines and murine Dnmt-WT and Dnmt-TKO ESCs. Briefly, total RNA was extracted using TRIzol (Invitrogen), and remaining DNA contaminants in 17-20 $\mu \mathrm{g}$ of RNA were removed using Turbo DNase (Ambion) according to the manufacturer's instructions. RNA was repurified using the RNeasy Mini Kit (Qiagen). For total RNA-seq, ribosomal RNA present was depleted from $5 \mu \mathrm{g}$ of total RNA using the RiboMinus Eukaryote System (Life technologies). cDNA synthesis was performed using the SuperScript ${ }^{\circ}$ III Reverse Transcriptase kit (Invitrogen). Three micrograms of random Primers (Invitrogen), $8 \mu \mathrm{L}$ of $5 \times$ first-strand buffer, and $10 \mu \mathrm{L}$ of RNA mix were incubated at $94{ }^{\circ} \mathrm{C}$ for 3 min and then at $4{ }^{\circ} \mathrm{C}$ for 1 min. Next, $2 \mu \mathrm{L}$ of $10 \mathrm{mM}$ dNTP Mix (Invitrogen), $4 \mu \mathrm{L}$ of $0.1 \mathrm{M}$ DTT, $2 \mu \mathrm{L}$ of SUPERase• $\mathrm{In}^{\mathrm{Tw}}$ RNase Inhibitor $20 \mathrm{U} / \mu \mathrm{L}$ (Ambion), $2 \mu \mathrm{L}$ of SuperScript ${ }^{\mathrm{Tm}}$ III RT (200 units $/ \mu \mathrm{L}$ ), and $8 \mu \mathrm{L}$ of Actinomycin D $(1 \mu \mathrm{g} / \mu \mathrm{L})$ were added, and the mix was incubated $5 \mathrm{~min}$ at $25^{\circ} \mathrm{C}, 60 \mathrm{~min}$ at $50^{\circ} \mathrm{C}$, and $15 \mathrm{~min}$ at $70^{\circ} \mathrm{C}$ to heat-inactivate the reaction. The cDNA was purified using $80 \mu \mathrm{L}$ ( $2 \times$ volume) of Agencourt AMPure XP and eluted in $50 \mu \mathrm{L}$ of 
the following mix: $5 \mu \mathrm{L}$ of $10 \times$ NEBuffer $2,1.5 \mu \mathrm{L}$ of $10 \mathrm{mM}$ dNTP mix (10 mM dATP, dCTP, dGTP, dUTP, Sigma), $0.1 \mu \mathrm{L}$ of RNaseH (10 U/ $\mu \mathrm{L}$, Ambion), $2.5 \mu \mathrm{L}$ of DNA Polymerase I Klenov $(10 \mathrm{U} / \mu \mathrm{L}, \mathrm{NEB})$, and water until $50 \mu \mathrm{L}$. The eluted cDNA was incubated for $30 \mathrm{~min}$ at $16^{\circ} \mathrm{C}$, purified by Agencourt AMPure XP, and eluted in $30 \mu \mathrm{L}$ of dA-Tailing mix ( $2 \mu \mathrm{L}$ of Klenow Fragment, $3 \mu \mathrm{L}$ of $10 \times$ NEBNext dA-Tailing Reaction Buffer, and $25 \mu \mathrm{L}$ of water). After $30 \mathrm{~min}$ incubation at $37^{\circ} \mathrm{C}$, the DNA was purified by Agencourt AMPure XP, eluted in TE buffer, and quantified on NanoDrop. Subsequent library preparation was done using the DNA library prep master mix set, and sequencing was performed as described for ChIP-seq.

mRNA capture and stranded library preparation of RNA from MCF7 cells, mouse cell lines, and tumors for the purpose of retrotransposon and cryptic transcript expression analysis was performed using the KAPA Stranded mRNA-Seq Kit according to the provided protocol (Illumina). For expression analysis of coding genes, RNA-seq reads were mapped to the human or murine genome reference (hg19 or mm10) using Tophat2. Gene read numbers were counted using HTSeq and normalized to the sum of the mapped expression counts. Gene expression was presented as transcript per million (TPM), 0.01 offset. Differential gene expression was tested using edgeR.

Expression of cancer testis antigens was annotated according to all entries listed in the CTDatabase (www.cta.lncc.br/modelo.php). Cytolytic activity was quantified as the log average (geometric mean in TPM) of the RNA expression of 2 key cytolytic enzymes: granzyme A (GZMA) and perforin 1 (PRF1).

\section{RepEnrich analyses}

RNA-seq data were expressed in TPM with an offset of 0.01. Expression read counts of retrotransposons are calculated using the RepEnrich tool (https://github.com/nerettilab/RepEnrich) and normalized to the total mappable read depth. The repeat genome of the human reference genome hg19 was downloaded from the RepEnrich website. Human retrotransposon classes (LINE, SINE, LTR) contain 16 families and 779 subfamilies. The repeat genome of the mouse genome mm10 was built using the RepeatMasker track from the UCSC genome browser. Mouse retrotransposon classes (LINE, SINE, LTR) contain 24 families and 906 subfamilies.

\section{CREDENToR analysis}

The overall strategy of CREDENToR is to perform de novo assembly of all reads and based on this define all cryptic transcripts. CREDENToR will consider transcripts encompassing more than one repeat element as one cryptic transcript and quantify gene expression for each of them. To achieve this, fastq files of RNA-seq data were first aligned to the human (build GRCh38) or the murine genome (build mm10) using STAR (version 2.5) with a tolerance of two mismatches. Transcriptomes were subsequently assembled using StringTie [61] (version 1.3.4d), under guidance of the transcript annotation tool Ensembl 92. All de novo assembled transcription annotations from the same set of tumor samples (i.e., MCF7 or 4T1 cell lines, or each of the 14 tumor types downloaded from TCGA) were merged using "StringTie --merge". HTSeqcounts [62] (version 0.11.2) were used to count the read numbers of known and novel genes. Noncoding transcripts (transcripts not overlapping annotated coding genes) in 
the merged transcription annotations were assigned as cryptic transcripts when any of their exons overlapped with a retrotransposon repeat annotation (LTR, LINE, or SINE, based on RepeatMasker annotation from UCSC). If a transcript overlapped with $>1$ annotated repeat, the retrotransposon with the highest overlap was assigned to this cryptic transcript.

For the analysis of MCF7 data, the assembled annotations from all experimental conditions involving MCF7 cells assessed in vitro were merged before read counting. For the analysis of 4T1 data, the assembled annotations from in vitro and in vivo samples were merged together. Cryptic transcripts were considered to be HIF-associated if a HIF binding summit was detected within the transcript promoter (i.e., $2000 \mathrm{bp}$ upstream and 500 bp downstream of the transcription start site). Per set of experiments (24 samples), we further required that the read number per cryptic transcript exceeds 10 in at least 1 sample and that the reads per kb per million reads (RPKM) exceed 1 in at least one sample. For these cryptic transcripts, DESeq (version 1.30.0) was used to test the differences between each pair of conditions. For the TCGA data, we merged assembled transcription annotations for each tumor type separately. Cryptic transcripts were calculated using the total cryptic transcript read count divided by the total coding gene read count. In volcano plots, individual cryptic transcripts were plotted, but in violin plots, where we compare effects to the cryptic transcripts obtained by RepEnrich, we summed cryptic transcript counts into retrotransposon subfamilies, log-transferred counts-per-million (normalized to total read counts), and considered those as expression values. Violin plots invariably show $>95 \%$ of data points. $P$ values were corrected for multiple testing following Benjamini and Hochberg correction. The CREDENToR pipeline has been made available on GitHub (https://github.com/Jieyi-DiLaKULeuven/CREDENToR).

\section{Gene ontology analysis}

Genes were associated to ontologies as annotated in BioMART (Ensembl GRCh37 release 84), and enrichment of ontologies was analyzed using TopGo (version 1.0) in $R$ [63], using the classic algorithm, contrasting to all protein-coding genes.

\section{Structural modeling of DNA methylation}

The crystal structure of HIF2 $\alpha: H I F 1 \beta$ in complex with DNA containing the RCGTG core sequence 5' -ACGTG-3' ([25], PDB code 4ZPK) was used as a template for introducing and analyzing the structural consequences of methyl groups at position 5 of the cytosines using the programs PyMOL (Schrodinger, LLC) and Chimera [64].

\section{Microscale thermophoresis (MST) binding assay}

MST measurements were performed in triplicate using the NanoTemper Monolith NT.115 instrument. The two protein complexes (HIF1 $\alpha$-HIF1 $\beta$ and HIF2 $\alpha$-HIF1 $\beta$ ) were purified as described earlier [25]. They were both labeled using Monolith NT Protein labeling kit RED-NHS (Nano Temper technologies). Oligonucleotides were from IDT. In brief, $25 \mathrm{nM}$ of each labeled protein was mixed in 16 serial dilutions of 1:1 with different DNA concentrations starting from a concentration of $25 \mu \mathrm{M}$. The experiment was carried out in $20 \mathrm{mM}$ phosphate buffer, $75 \mathrm{mM} \mathrm{NaCl}, 5 \mathrm{mM}$ DTT, $0.05 \%$ Tween20 , and $\mathrm{pH}$ 7.4. Samples were incubated for $20 \mathrm{~min}$ on ice prior to loading $5 \mu \mathrm{L}$ of each sample into the standard treated capillaries. MST measurements were carried out at 
$25^{\circ} \mathrm{C}$ at $20 \%$ LED power and medium MST power. Data was normalized to \% fraction bound, and the values for the equilibrium dissociation constant $\left(K_{\mathrm{D}}\right)$ were calculated by fitting the curves in GraphPad Prism 7.

\section{Generation of mESCs containing a methylated or unmethylated HIF binding region}

A DNA fragment (human chr16:30,065,212-30,065,711) containing five CGTG motives was selected based on high HIF1 $\beta$ ChIP-enrichment in MCF7, RCC4, and SK-MEL-28 cells. Oligonucleotides were designed to amplify the target region (AGGTGCAATT GTTCCTCCGCCTCCCTTAC and AAGGGCAATTGCCGAGCTTTTTCCTTTACGA) and used for PCR amplification of the target region using the Q5 $5^{\circ}$ Hot Start High-Fidelity $2 \times$ Master Mix (NEB), followed by evaluation of the PCR products by gel electrophoresis and purification with the Qiaquick PCR purification kit (28104, Qiagen). These PCR primers were evaluated for specificity in human (MCF7, RCC4, SK-MEL-28) but not in mouse genomic DNA, while MfeI restriction sites were added to the ends of the primer pairs. The purified amplicon was digested with MfeI and cloned into the L1-poly-L1 plasmid (provided by Prof. Dirk Schubeler, Friedrich Miescher Institute for Biomedical Research, Basel, Switzerland), containing a multiple cloning site flanked by two inverted L1 Lox sites. Correct insertion and sequence identity were verified by Sanger sequencing. This plasmid was in vitro methylated using M.SssI (NEB) according to the manufacturer's instructions and purified using isopropanol precipitation. Successful and complete in vitro methylation was confirmed by bisulfite-conversion (EZ DNA Methylation-Lightning Kit, D5031, Laborimpex), PCR amplification using the MegaMix Gold 2× Mastermix (Microzone), and Sanger sequencing. Ten micrograms of pIC-CRE plasmid and $25 \mu \mathrm{g}$ of (un)methylated plasmid were electroporated in murine ES 159 cells containing an L1flanked thymidine kinase expression cassette (provided by Prof. Dirk Schubeler, Friedrich Miescher Institute for Biomedical Research, Basel, Switzerland). After electroporation, cells were plated and maintained in nonselective ES medium for 1 day and, from the second day onwards, cultured in ES medium containing $10 \mu \mathrm{M}$ ganciclovir. After 10 to 12 days, individual clones of the surviving cells were picked and transferred to ES medium in 96-well plates, then gradually expanded and, following DNA extraction, assessed for occurrence of successful insertion events using PCR (using the following oligonucleotides: AGGTGCAATTGTTCCTCCGCCTCCCTTAC and AAGGGCAATTGCCGAGCT TTTTCCTTTACGA) and gel electrophoresis.

To verify maintenance of the methylation levels of the cloned HIF binding site, genomic DNA was extracted from a positive clone. Then, $500 \mathrm{ng}$ of DNA was bisulfiteconverted using the EZ DNA Methylation-Lightning Kit (D5031, Laborimpex) and amplified using the MegaMix Gold 2× Mastermix and validated primer pairs for the target locus (Forward: GTTTGGGTTAGTGATAGGGTGT, Reverse: AAACCCTCCC TTCTACTCCTTTCC). Per sample, PCR product sizes were verified by gel electrophoresis, and amplicons converted into sequencing libraries using the NEBNext DNA library prep master mix set (E6040L, Bioke). These were next sequenced to a depth exceeding 500×, and mapped and analyzed as described higher.

Positive colonies were expanded into $10-\mathrm{cm}$ dishes and subjected to ChIP as described above. qPCR was performed with the SYBR GreenER ${ }^{\mathrm{m}}$ qPCR SuperMix Universal (11762500, Life Technologies) on a Quantstudio 12K (Applied Biosystems), by using 
specific primers for the cloned locus (oligonucleotides TCGTTTCCGACTTTTCCATC and CAGCCAGAATGTTGGCAAT) and an independent murine genomic region for background quantification (oligonucleotides CACTTGCTGAATAATTGGGTGT and CTGTTGTCCAGTTTTCTTCACG). Enrichment was calculated as fold enrichment over background.

\section{TCGA samples and data analysis}

From the TCGA server, we selected 5193 tumors from 14 tumor types: 413 bladder urothelial carcinoma (BLCA), 664 breast cancer (BRCA), 303 cervical squamous cell carcinoma and endocervical adenocarcinoma (CESC), 201 colon adenocarcinoma (COAD), 497 head and neck squamous cell carcinoma (HNSC), 269 kidney renal papillary cell carcinoma (KIRP), 372 liver hepatocellular carcinoma (LIHC), 460 lung adenocarcinoma (LUAD), 368 lung squamous cell carcinoma (LUSC), 175 pancreatic adenocarcinoma (PAAD), 498 prostate adenocarcinoma (PRAD), 465 skin cutaneous melanoma (SKCM), 338 stomach adenocarcinoma (STAD), and 171 uterine corpus endometrial carcinoma (UCEC) for which RNA data were available. The corresponding RNA-seq read counts were downloaded. DNA methylation data from Infinium HumanMethylation450 BeadChip arrays available were downloaded for the same samples.

Tumor types were classified as responsive or non-responsive to checkpoint immunotherapy following the classification described by Turajlik and colleagues [38], with three notable exceptions. Firstly, kidney renal papillary cell carcinoma (KIRP) was classified as non-responsive as no study has yet demonstrated responsiveness of this tumor type. Secondly, clear cell kidney carcinoma (KIRC) tumors were not analyzed, as the HIFconstitutive activation in these tumors (due to VHL-loss) precludes their classification into a hypoxic and normoxic subset. Finally, also microsatellite-instable COAD tumors were discarded from all analyses, as these tend to show constitutive hypermethylation, precluding their stratification in high and low methylation subgroups [65]. Importantly, the tumor types that we define as responsive will still contain tumors that fail to respond, whereas the non-responsive tumor types will also contain a minority of tumors that do respond to immunotherapy. For instance, a subset of triple-negative breast tumors responds to checkpoint immunotherapy. Likewise, there is evidence that a small subset of LIHC tumors also responds and that microsatellite-instable tumors also occur in UCEC tumors. Cryptic transcription loads were calculated using the total cryptic transcript read count divided by the total coding gene read count.

For the methylation stratification, the beta values of HM450K methylation microarray data were downloaded from TCGA. Probes overlapping the cryptic transcript promoter (i.e., $2000 \mathrm{bp}$ upstream and $500 \mathrm{bp}$ downstream of the transcription start site) were regarded as cryptic transcription-associated probes. For each tumor, its promoter methylation level was calculated as the mean beta value of all cryptic transcriptionassociated probes. All tumors were then classified into high and low methylation groups based on the median value of methylation levels.

To identify which of these tumor samples were hypoxic or normoxic, we performed unsupervised hierarchical clustering based on a modification of the Ward error sum of squares hierarchical clustering method (Ward.D of the clusth function in R's stats package) on normalized log-transformed RNA-seq read counts for 15 genes that make up 
the hypoxia metagene signature (ALDOA, MIF, TUBB6, P4HA1, SLC2A1, PGAM1, ENO1, LDHA, CDKN3, TPI1, NDRG1, VEGFA, ACOT7, CDKN3, and ADM) [37]. In each case, the top 2 subclusters identified were annotated as normoxic and hypoxic.

To test the interaction between hypoxia and DNA methylation, we assessed read counts for cryptic transcripts in two negative-binominal generalized linear models with both oxygenation (hypoxic and normoxic; encoded as 0 and 1) and methylation (low and high methylation; encoded as 0 or 1 ), with or without an interaction term. Both models were compared to each other using DESeq. A positive interaction coefficient represents a cooperative enhancement of cryptic transcript expression in lowmethylation, hypoxic tumors. To further enrich for tumors that are prone to respond to checkpoint immunotherapy, we stratified all tumor types into high PDL1 mRNA expressing and low PDL1 mRNA expressing tumors, and into tumors with a high or low tumor mutation burden (TMB). Stratification was done on the third decile in both cases. TMB was estimated based on the number of substitutions identified by TCGA in each tumor sample. All substitutions were considered, except for those also present in non-malignant samples (i.e., exclusion of germline variants) or those clustering within and across different samples (and therefore most likely representing sequencing or mapping errors).

\section{Single-cell analysis}

We used CREDENToR to map cryptic transcript expression in each individual cell from a public single-cell RNA-seq dataset [66]. The cryptic transcript annotation was obtained from the CREDENToR analysis of lung TCGA tumors (LUAD and LUSC). CellRanger (version 1.1.0) was used as the mapping tool. The annotation of each individual cell is as previously defined in Lambrechts et al. [66].

To study the effect of hypoxia and DNA methylation on cryptic transcript expression, we used a public single-cell dataset GSE97693 [39]. Single-cell RNA-seq reads were downloaded and mapped using STAR (version 2.5). Cancer cells for which the number of uniquely mapped reads exceeded $30 \%$ were stratified into hypoxic cells and normoxic cells as described higher. The cryptic transcript annotation was obtained from COAD tumors in TCGA. We selected 458 cryptic transcripts expressed in at least $20 \%$ of cells. Methylation was defined as the number of methylated CpGs over the total number of CpGs in a region $2 \mathrm{~kb}$ downstream and $500 \mathrm{bp}$ upstream of the cryptic transcript transcription start site.

\section{T1 Hif1b-knockout}

Four gRNAs targeting two different exons in the Hiflb locus of the mouse genome and one non-targeting gRNA (scramble) were designed with the appropriate restriction sites for the receiver plasmid using the online Crispor tool (http://crispor.tefor.net). Oligonucleotides corresponding to gRNAs were synthesized by IDT, and forward and reverse oligonucleotides were annealed in the CutSmart buffer (B7240S, NEB) before cloning into the LentiGuide-Puro plasmid (Plasmid 52963, Addgene). Positive colonies were screened by PCR and validated by Sanger sequencing. LentiGuide-Puro plasmids containing GFP were used as positive control to evaluate the transfection and transduction efficacy. 
A transformation mix containing viral particles, TE, $\mathrm{CaCl}_{2}, \mathrm{H}_{2} \mathrm{O}$, and LentiGuidePuro plasmid was added to HEK $293 \mathrm{~T}$ cells when reaching $70 \%$ confluency. Four plasmids containing the different gRNAs for Hiflb and one plasmid containing the scramble gRNA were used, together with plasmids containing GFP as positive control. Medium was renewed after $14-16 \mathrm{~h}$, and transfection efficiency was evaluated based on GFP expression. After $36 \mathrm{~h}$, supernatant containing the concentrated virus was collected by ultracentrifugation. Virus was dissolved in clean PBS and stored at $-150^{\circ} \mathrm{C}$.

$4 \mathrm{~T} 1$ cells were transduced with a lentiviral vector expressing a doxycycline-inducible Cas9 nuclease (Cat \# CAS11229, Dharmacon) for a tight regulation of the Cas9 expression and gene editing. An infection rate of $30 \%$ was used to ensure that the majority of transduced cells harbor a single copy of the vector. These 4T1 cells were always kept in selection medium containing $10 \mu \mathrm{g} / \mathrm{mL}$ of blasticidin (ant-bl-05, Invivogen). When reaching $70 \%$ confluency, cells were transduced with one titer of virus. After $24 \mathrm{~h}$, the virus was removed and transduction efficacy evaluated based on GFP expression. After $48 \mathrm{~h}$, puromycin (P9620, Sigma-Aldrich) $1.5 \mu \mathrm{g} / \mathrm{mL}$ medium was added to the medium. Cells were kept in the presence of blasticidin and puromycin for the remaining experimental procedures. After 3-5 days, Cas9 expression was induced by adding doxorubicin (D2975000, Sigma-Aldrich) $0.5 \mu \mathrm{g} / \mathrm{mL}$ medium for 3 days. Cells were kept 1 day without doxorubicin before injection in the mice or further experimental procedures. 4T1 cells transduced with the four gRNAs targeting Hiflb were expanded, and proteins were extracted to test the efficacy of the knockout by Western blot. The most efficient gRNA was used to perform the further experiments (F: CACCGTGAAATAGAACGG CGGCGA and R: AAACTCGCCGCCGTTCTATTTCAC; non-targeting F: CACCGC ACTACCAGAGCTAACTCAG and non-targeting R: AAACCTGAGTTAGCTCTG GTAGTGC). Stability of knockout in these polyclonal 4T1 cells after 2 weeks was confirmed by Western blot.

\section{Mouse tumor model}

All the experimental procedures were approved by the Institutional Animal Care and Research Advisory Committee of the KU Leuven. $1 \times 10^{6} 4 \mathrm{~T} 1$ cells, 4T1 Hif1b-knockout, or wild-type 4T1 cells (scramble) were injected orthotopically in the mammary gland of 10 weeks old Balb/c mice, and $1 \times 10^{6}$ CT26 or MC38 cells were injected subcutaneously in 10 weeks old Balb/c or C57BL/6J mice respectively. When the tumor was palpable (starting volume $100 \mathrm{~mm}^{3}$ ), the mice were injected intraperitoneally with $0.8 \mathrm{mg} / \mathrm{kg}$ of 5 -aza-2'-deoxycytidine (aza) or PBS, $40 \mathrm{mg} / \mathrm{kg}$ DC101 antibody (BE0089, InVivoMab) or IgG (BE0060, InVivoMab), or $10 \mathrm{mg} / \mathrm{kg}$ anti-PD1 antibody (BE0146, InVivoMab) or IgG (BE0089, InVivoMab) according to the following schedules: DC101 three times per week; anti-PD1 every other day, starting when the tumor size was around $200 \mathrm{~mm}^{3}$; aza was administered in 2 cycles with 2 days rest in between until the control tumors reached the endpoint. Tumor volumes were monitored every 2 to 3 days by a caliper, and mice were culled before tumor volumes exceeded $2000 \mathrm{~mm}^{3}$. When over $20 \%$ of mice were culled, the experiment was terminated (all arms). In vivo experiments in 4T1, CT26, and MC38 treated with aza or anti-PD1 antibody were performed three times, with at least 6 mice per treatment group in each experiment. 
Neo-epitope burden

To assess neo-epitope burden, we mapped RNA sequencing data of isogenic 4T1, B16, and CT26 tumor models, removed duplicate reads from individual samples, and merged per tumor model all samples into a single file. In this file, variants were called according to GATK best practices, using GATK3.4. Briefly, reads were split into exon segments and sequences overhanging the non-exonic regions were hard-clipped using split'n'trim. Next, local indel realignment and base recalibration was performed, followed by variant calling with GATK's HaplotypeCaller. After quality filtering for minimal Fisher strand values (30) and minimal read depth (10-fold), we removed SNPs reported in the Sanger Mouse project (rsIDdbSNPv137). Remaining variants were annotated by Annovar (version 2.17.0), and only variants in coding regions were retained. Finally, the neo-epitope burden was expressed as the number of non-SNP variants in coding sequences, normalized to the number of coding sequences that were expressed, the latter being defined as having a minimal read depth of 10 .

\section{Immunofluorescence analysis of tumor sections}

Different protocols were applied depending on the epitope of interest: hypoxia (pimonidazole) staining was combined with blood vessel (CD31) staining, and cytotoxic $\mathrm{T}$ cell activity (granzyme B) with T cell infiltration (CD8a) staining. General (CD45) and cytotoxic (CD8a) T cell infiltration stainings were performed separately. Tumors were harvested, fixed in formaldehyde, and embedded in paraffin using standard procedures. Slides were deparafinated and rehydrated in 2 xylene baths $(5 \mathrm{~min})$, followed by 5 times $3 \mathrm{~min}$ in $\mathrm{EtOH}$ baths at decreasing concentrations (100\%, 96\%, 70\%, 50\%, and water) and a 3 min Tris-buffered saline (TBS; $50 \mathrm{mM}$ Tris, $150 \mathrm{mM} \mathrm{NaCl,pH} \mathrm{7.6)} \mathrm{bath.} \mathrm{Anti-}$ gen retrieval was done using $\mathrm{AgR}$ (DAKO) at $100^{\circ} \mathrm{C}$ for $20 \mathrm{~min}$, followed by cooling for $20 \mathrm{~min}$. Slides were washed in TBS for $5 \mathrm{~min}$, and endogenous peroxidase activity was quenched using $\mathrm{H}_{2} \mathrm{O}_{2}(0.3 \%$ in $\mathrm{MeOH})$, followed by three 5 -min washes in TBS. Slides were blocked using pre-immune goat serum (X0907, Dako) or pre-immune rabbit serum (for pimonidazole, X090210, Dako) 20\% in TNB. Binding of primary antibodies FITC-conjugated mouse anti-pimonidazole (HP2-100, Hydroxyprobe), rabbit antiGzmb (ab4059, Abcam), and rat anti-CD45 (553,076, BD Biosciences) all 1:100 in TNB was allowed to proceed overnight. Slides were washed 3 times in TNT $(0.5 \%$ Triton$\mathrm{X} 100$ in TBS) for $5 \mathrm{~min}$, after which secondary antibodies peroxidase-conjugated rabbit anti-FITC (PA1-26804, Pierce), Alexa Fluor 488-conjugated goat anti-rabbit (A-11034, Thermo Fisher), and biotinylated goat anti-rat (559286, BD biosciences) all 1:100 in TNB with $10 \%$ pre-immune goat serum were allowed to bind for $1 \mathrm{~h}$. Slides were washed 3 times for $5 \mathrm{~min}$ in TNT, after which signal amplification was done by $30 \mathrm{~min}$ incubation with peroxidase-conjugated streptavidin 1:100 in TNB (for all besides pimonidazole) accompanied by nuclear staining with Hoechst (H3570, Thermo Fisher) 1:500 in TNB only for the single (CD45 or CD8a) stainings, washing ( 3 times $5 \mathrm{~min}$ in TNT), and $8 \mathrm{~min}$ incubation using fluorescein tyramide (for pimonidazole NEL701A001KT, Perkin Elmer) or Cy3 (NEL704A001KT, Perkin Elmer) 1:50 in amplification diluent.

Slides stained for pimonidazole and Gzmb required co-staining for CD31 and CD8a respectively and were subjected to a second indirect staining for the latter epitopes. After $5 \mathrm{~min}$ of TNT and $5 \mathrm{~min}$ of TBS, slides were quenched again for peroxidase 
activity using $\mathrm{H}_{2} \mathrm{O}_{2}$ and blocked using pre-immune goat or rabbit (CD31) serum, prior to a second overnight round of primary antibody binding: rat anti-CD31 (557355, BD Biosciences) or rat anti-CD8a (14-0808-82, Thermo Fisher) 1:100 in TNB. The next day, 3 times $5 \mathrm{~min}$ washes with TNT were followed by a $1 \mathrm{~h}$ incubation with biotinylated goat anti-rat (559286, BD biosciences) 1:100 in TNB, again 3 times 5 min washes with TNT, a 30-min incubation with peroxidase-conjugated streptavidine 1:100 in TNB accompanied by nuclear staining with Hoechst (H3570, Thermo Fisher) 1:500 in TNB, 3 times $5 \mathrm{~min}$ washes with TNT and signal amplification for $8 \mathrm{~min}$ using Cy3 (NEL704A001KT, Perkin Elmer) 1:50 in amplification diluent. Finally, slides were washed 3 times for 5 min with TNT and mounted with Prolong Gold (P36930, Life Technologies).

For immunofluorescence analysis on 4T1 wild-type tumors, slides were imaged on an infraMouse Leica DM5500 microscope. Four sections from different treatment groups were stained per slide while 6 pictures from different tumor areas were used for processing with ImageJ. More specifically, nuclei were identified using the Hoechst signal, and signal intensities for fluorescein (pimonidazole), Alexa Fluor 488 (Gzmb), and Cy3 (CD45, CD8a and CD31) were used to detect $\mathrm{Gzmb}^{+}, \mathrm{CD}^{+} 5^{+}$, and/or CD8a ${ }^{+}$cells. Analyses were exclusively performed on slide regions showing a regular density and shape of nuclei, in order to avoid inclusion of acellular or necrotic areas. $\mathrm{Gzmb}^{+} \mathrm{CD} 8 \mathrm{a}^{+}$cells were counted directly, allowing the precise quantification of the number of active cytotoxic $\mathrm{T}$ cells per tumor. The number of $\mathrm{CD} 45^{+}$cells was used to normalize the number of $\mathrm{CD} \mathrm{a}^{+}$cells, as such calculating the number of infiltrating cytotoxic $\mathrm{T}$ cells compared to the total immune infiltration. CD31-positive regions were quantified manually using ImageJ. The pimonidazole signal was used together with the Hoechst signal to quantify the percentage of hypoxia per tumor area in each picture and stratify tumors as hypoxic (pimo-high) or normoxic (pimo-low).

For immunohistofluorescence on 4T1 Hif1b-knockout or Hif1b-scramble grafts, tumors were harvested and snap frozen in liquid nitrogen before temporary storage at $80^{\circ} \mathrm{C}$. Thawed tumors were embedded in paraffin and sectioned using standard procedures ( $5 \mu \mathrm{m}$ of thickness). In a Leica Autostainer (30 min), slides were deparafinated and rehydrated in 2 xylene baths for $5 \mathrm{~min}$, followed by $5 \mathrm{~min}$ in ethanol baths at decreasing concentrations (100\%, 96\%, 70\%, 50\%, and water). Slides were fixed in 10\% neutral buffered formalin for $10 \mathrm{~min}$ and rinsed twice in double-distilled water. Antigen retrieval proceeded in AR6 buffer (AR600, PerkinElmer) at $100{ }^{\circ} \mathrm{C}$ for $23 \mathrm{~min}$ in a pressure cooker, followed by cooling in double-distilled water for $20 \mathrm{~min}$. Slides were washed in TBST (TBS with 0.5\% Tween 20) for 3 min and blocked using blocking buffer (pre-immune goat serum (X0907, Dako) 10\%, 1\% BSA (126575, Millipore) in TBS)) for $30 \mathrm{~min}$. The primary antibody (rabbit anti-Gzmb) 1:1000 in dilution buffer (1\% BSA in TBS) was applied for $30 \mathrm{~min}$ at RT, followed by 3 washes of $2 \mathrm{~min}$ in TBST at RT. Slides were next incubated with the secondary antibody (EnVision ${ }^{\mathrm{Tm}}+/$ HRP goat antirabbit (K4003, Dako)) for $10 \mathrm{~min}$ at RT and washed 3 times for 2 min in TBST at RT. The OPAL 570 fluorophore (fp1488, PerkinElmer) 10\% in amplification diluent (FP1498, PerkinElmer) was applied for $10 \mathrm{~min}$ at RT followed by 3 washes of $2 \mathrm{~min}$ in TBST at RT. Slides were stripped by heating in AR6 buffer just below the boiling point and cooled down in double-distilled water, followed by rinsing in TBST. These steps were repeated starting from blocking for the second staining with primary antibody rat 
anti-CD8a 1:300, secondary antibody goat anti-rat (MP-7444, Vector) and opal 690 (fp1497, PerkinElmer), and the third staining with rat anti-CD45 1:1000, secondary antibody goat anti-rat, and Opal 520 (fp1487, PerkinElmer). After the third staining, slides were incubated with spectral DAPI (fp1490, PerkinElmer) 10\% in TBST for $5 \mathrm{~min}$ at RT, washed for $2 \mathrm{~min}$ in TBST at RT, and mounted with ProLong Diamond Antifade Mountant (P36961 Invitrogen). Images were acquired on a Zeiss Axio Scan.Z1 using a $\times 20$ objective and ZEN 2 software (Zeiss) with exposure times between 10 and $50 \mathrm{~ms}$. Image processing was done using QuPath (version 0.1.2). Specifically, following visual inspection of the staining results, cells were first automatically detected using the DAPI channel (cell size constrained between 5 and $400 \mu \mathrm{m}^{2}$ ). Next, a cell classifier was generated using QuPath. Specifically, for 1 slide out of all slides, 5 sets of cells were selected: one set that was positive for $\mathrm{CD} 45$, one set that was negative for $\mathrm{CD} 45$, and three sets of $\mathrm{CD} 45^{+}$cells positive for CD8, Gzmb and CD8, or Gzmb alone. Using these 5 sets of cells, a random trees classifier was generated. Cell classification was visually verified to have occurred correctly. Next, in each tumor section, a representative region was selected, containing at least 1000 cells. On these cells, the random trees classifier was subsequently applied. This process was reiterated for all other tumor sections stained for the same set of markers. The resulting cell identities were then exported and processed in R. For each tumor, average cell frequencies were generated, which were summarized using boxplots.

\section{Immunofluorescence analysis of $4 \mathrm{~T} 1$ cells}

For the dsRNA staining on 4T1 cells, 12.000 cells were seeded on gelatin-coated glass slips in 12-well plates on day 0 . After attaching for $6 \mathrm{~h}$, cells were treated with aza or control (DMSO) for 3 days, with renewal of the medium after $48 \mathrm{~h}$. After $72 \mathrm{~h}$, the medium was refreshed and cells were incubated in hypoxia or normoxia for $16 \mathrm{~h}$. After washing 3 times with PBS, cells were fixed in $1 \mathrm{ml}$ of ice-cold methanol for $15 \mathrm{~min}$ at $20^{\circ} \mathrm{C}$. Cells were washed 3 times with PBS and blocked for $1 \mathrm{~h}$ with blocking buffer (0.1\% triton X-100 with $5 \%$ goat serum in PBS). Primary antibody (1:50 dilution in blocking buffer; clone J2, Scicons) was applied overnight at $4{ }^{\circ} \mathrm{C}$. Cells were washed 3 times for 10 min with washing buffer $(0.1 \%$ triton X-100 in PBS) and secondary antibody (1:500 in secondary antibody buffer $(0.1 \%$ triton X-100 with $2 \%$ goat serum in PBS)). Goat anti-mouse IgG coupled to Alexa 488, Life Technologies) was applied for $1 \mathrm{~h}$ in the dark. Cells were washed 3 times for $10 \mathrm{~min}$ with washing buffer and mounted with DAPI stain on cover glasses. Slides were imaged on an infraMouse Leica DM5500 microscope. Three slides from different treatment groups were stained in triplicate (biological replicates), while 3 pictures from different slides were used for processing with ImageJ. More specifically, nuclei were identified using the DAPI signal, and nucleated cells were further selected based on particle size. Signal intensities for Alexa Fluor 488 in the selected cells were used to detect dsRNA ${ }^{+}$cells. Analyses were exclusively performed on slide regions showing a regular density and shape of nuclei, in order to avoid inclusion of acellular or necrotic areas. Mean dsRNA expression was calculated per experiment, normalized to the background signal (secondary antibody only), and expressed as mean pixel intensity relative to the control group (normoxia + DMSO). 


\section{Supplementary information}

Supplementary information accompanies this paper at https://doi.org/10.1186/s13059-020-02087-z.

Additional file 1: Fig. S1. HIF1 $\beta$ peaks in MCF7 cells under $0.5 \%$ O2. Fig. S2. Expression of hypoxia genes and cancer testis antigens. Fig. S3. Cell-type-specific HIF1 $\beta$ binding. Fig. S4. DNA methylation directly repels HIF1 $\beta$ binding. Fig. S5. Quality control of the ChIP-seq replicates. Fig. S6. HIF binds retrotransposons in demethylated genomes. Fig. S7. Examples of cryptic transcripts upregulated by HIF1ß. Fig. S8. Cryptic transcript expression in TCGA tumors. Fig. S9. Aza treatment increases immunogenicity.

Additional file 2: Table S1. HIF1 $\beta$ binding peaks detected using MACS at $P<10^{-15}$ in MCF7 cell line.

Additional file 3: Table S2. HIF1 $\beta$ binding peaks detected using MACS at $P<10^{-15}$ across RCC4, MCF7 and SKMEL-28 cell lines. For each cell line, HIF1 $\beta$ binding was annotated as 'present' if the peak area showed $>4$-fold enrichment over the local read depth, and as 'absent' if it showed $<2.5$-fold enrichment; intermediate enrichment scores were annotated as 'unclassified'.

Additional file 4: Table S3. Cryptic transcript promoter DNA methylation and expression levels. Shown are results from an analysis of combined single-cell methylome-and-transcriptome sequencing of colorectal cancer cells, as generated by Bian and colleagues [38].

Additional file 5. Review history.

\section{Acknowledgements}

We thank Masaki Okano and Guoliang Xu for murine Dnmt-TKO and Tet-TKO ESCs and the corresponding matching WT ESCS.

\section{Review history}

The review history is available as Additional file 5 .

\section{Peer review information}

Anahita Bishop was the primary editor of this article and managed its editorial process and peer review in collaboration with the rest of the editorial team.

\section{Authors' contributions}

B.T., M.M., and D.L. contributed to the funding acquisition, supervision, and conceptualization; B.T., F.D.A, L.V.D., J.X., L.M., S.N.S., P.B.-K., L.S., J.M., J. Q., R. A., M.D.B., C.S., F.R., V.C., S.K., J.D.S., and P.C. contributed to the methodology; B.T., F.D.A., J.X., and H.Z. contributed to the software; B.T., F.D.A., L.V.D., H.Z., R.V.B, L.M., S.N.S., F.D., V. C., S.K., Q.Y., and L.Z. contributed to the formal analysis; B.T., F.D.A., H.Z., L.V.D., and J.X. contributed to the investigation; B.T., W.R., S.N.S., F.D.A, and D.L. contributed to the writing of the original draft. The author(s) read and approved the final manuscript.

\section{Authors' information}

Twitter handles: @VanDyckLaurien (Laurien Van Dyck); @RBerrens (Rebecca V. Berrens); @JunbinQian (Junbin Qian); @LiesbethMin (Liesbeth Minnoye); @MarieDeBorre (Marie De Borre); @MCSimonLab (Celeste Simon); @CarmelietLab (Peter Carmeliet); @ReikLab (Wolf Reik); @LabMazzone (Massimiliano Mazzone); @bernthie (Bernard Thienpont); @LambrechtsDlab (Diether Lambrechts).

\section{Funding}

This work was supported by grants from the ERC (CHAMELEON 617595 to D.L.; CHAMELEO 334420 to B.T.), Stichting tegen Kanker ('Foundation contre le Cancer): FAF-C/2016/876 and FWO: G070615N. Intensive computation was provided by the Flemish Supercomputer Center (VSC). H.Z. and B.T. were supported by FWO-F postdoctoral fellowships and L.V.D by an aspirant FWO fellowship.

\section{Availability of data and materials}

The dataset supporting the conclusions of this article is available in the Gene Expression Omnibus repository under the SuperSeries accession GSE85356, which is composed of subseries for ChIP-BS-seq (GSE85351), ChIP-seq (GSE85352), RNA-seq (GSE85353) and bisulfite-seq (GSE85354, GSE85355, and GSE152180) [67].

HIF1 $\beta, H I F 1 a, H I F 2 a$, and isotype ChIP-seq data from MCF7 cells were obtained from the Gene Expression Omnibus database under accession numbers GSM700947, GSM700944, GSM700945, and GSM700948.

WGBS data were obtained from the Gene Expression Omnibus database under accession number GSM1328112 for MCF7 cells [18] and under accession number GSM1127953 for WT mESC [68].

CTCF, FOXA1, and GATA3 ChIP-seq data from MCF7 cells were obtained from the Gene Expression Omnibus database under accession numbers GSM1003581, GSM1010727, and GSE41561 [17].

NOMe-seq data were obtained from the Gene Expression Omnibus database under accession number GSE57498 [23]. Single-cell RNA-seq data for lung tumors were obtained from ArrayExpress under accessions E-MTAB-6149 and EMTAB-6653 [66].

Single-cell RNA-seq and methylation data for colorectal tumors were obtained from the Gene Expression Omnibus database under accession number GSE97693 [39].

\section{Ethics approval and consent to participate}

All the experimental procedures on animals were approved by the Institutional Animal Care and Research Advisory Committee of the KU Leuven. 


\section{Competing interests}

The authors declare that they have no competing interests.

\section{Author details}

${ }^{1}$ Center for Cancer Biology, VIB, 3000 Leuven, Belgium. ${ }^{2}$ Laboratory of Translational Genetics, Department of Human Genetics, KU Leuven, 3000 Leuven, Belgium. ${ }^{3}$ Epigenetics Programme, Babraham Institute, Cambridge CB22 3AT, UK. ${ }^{4}$ The Old Schools, University of Cambridge, Trinity Lane Cambridge CB2 1TN, UK. ${ }^{5}$ Laboratory of Tumor Inflammation and Angiogenesis, Department of Oncology, KU Leuven, 3000 Leuven, Belgium. ${ }^{6}$ Target Discovery Institute, Nuffield Department of Medicine, University of Oxford, Oxford, UK. ${ }^{7}$ State Key Laboratory of Ophthalmology, Zhongsan Ophthalmic Center, Sun Yat-Sen University, Guangzhou, China. ${ }^{8}$ Laboratory of Angiogenesis and Vascular Metabolism, Department of Oncology, Leuven Cancer Institute, KU Leuven, 3000 Leuven, Belgium. ${ }^{9}$ Institute of Basic Medical Sciences, University of Oslo, 0372 Oslo, Norway. ${ }^{10}$ Laboratory of Dermatology, Department of Oncology, KU Leuven, 3000 Leuven, Belgium. ${ }^{11}$ Laboratory for Functional Epigenetics, Department of Human Genetics, KU Leuven, 3000 Leuven, Belgium. ${ }^{12}$ Unit for Structural Biology, Department of Biochemistry and Microbiology, Ghent University, 9052 Ghent, Belgium. ${ }^{13}$ VIB Center for Inflammation Research, 9052 Ghent, Belgium. ${ }^{14}$ Abramson Family Cancer Research Institute, Perelman School of Medicine, University of Pennsylvania, Philadelphia, PA 19104, USA. ${ }^{15}$ Department of Cell and Developmental Biology, Perelman School of Medicine, University of Pennsylvania, Philadelphia, PA 19104, USA. ${ }^{16} \mathrm{Centre}$ for Trophoblast Research, University of Cambridge, Cambridge CB2 3EG, UK. ${ }^{17}$ Wellcome Trust Sanger Institute, Hinxton, Cambridge CB10 1SA, UK. ${ }^{18}$ Department of Physiology, Development and Neuroscience, University of Cambridge, Cambridge CB2 3EG, UK. ${ }^{19} \mathrm{Clinical}$ and Experimental Endocrinology, Department of Chronic Diseases, Metabolism and Ageing, KU Leuven, 3000 Leuven, Belgium.

Received: 23 January 2020 Accepted: 29 June 2020

Published online: 27 July 2020

\section{References}

1. Thienpont B, Steinbacher J, Zhao H, D'Anna F, Kuchnio A, Ploumakis A, Ghesquiere B, Van Dyck L, Boeckx B, Schoonjans L, et al. Tumour hypoxia causes DNA hypermethylation by reducing TET activity. Nature. 2016;537:63-8.

2. Héberlé É, Bardet AF. Sensitivity of transcription factors to DNA methylation. Essays Biochem. 2019;63(6):727-41.

3. Ivan M, Kaelin WG Jr. The EGLN-HIF O2-sensing system: multiple inputs and feedbacks. Mol Cell. 2017;66:772-9.

4. Semenza GL. Targeting HIF-1 for cancer therapy. Nat Rev Cancer. 2003;3:721-32.

5. Casazza A, Di Conza G, Wenes M, Finisguerra V, Deschoemaeker S, Mazzone M. Tumor stroma: a complexity dictated by the hypoxic tumor microenvironment. Oncogene. 2014;33:1743-54.

6. Keith B, Johnson RS, Simon MC. HIF1alpha and HIF2alpha: sibling rivalry in hypoxic tumour growth and progression. Nat Rev Cancer. 2012;12:9-22.

7. Li W, Petrimpol M, Molle KD, Hall MN, Battegay EJ, Humar R. Hypoxia-induced endothelial proliferation requires both mTORC1 and mTORC2. Circ Res. 2007;100:79-87.

8. Palazon A, Tyrakis PA, Macias D, Veliça P, Rundqvist H, Fitzpatrick S, Vojnovic N, Phan AT, Loman N, Hedenfalk I. An HIF1a/NEGF-A axis in cytotoxic T cells regulates tumor progression. Cancer Cell. 2017:32:669-683. e665.

9. Schödel J, Oikonomopoulos S, Ragoussis J, Pugh CW, Ratcliffe PJ, Mole DR. High-resolution genome-wide mapping of HIF-binding sites by ChIP-seq. Blood. 2011;117:e207-217.

10. Chi JT, Wang Z, Nuyten DS, Rodriguez EH, Schaner ME, Salim A, Wang Y, Kristensen GB, Helland A, Borresen-Dale AL, et al. Gene expression programs in response to hypoxia: cell type specificity and prognostic significance in human cancers. PLoS Med. 2006;3:e47.

11. Sung FL, Hui EP, Tao Q, Li H, Tsui NB, Lo YM, Ma BB, To KF, Harris AL, Chan AT. Genome-wide expression analysis using microarray identified complex signaling pathways modulated by hypoxia in nasopharyngeal carcinoma. Cancer Lett. 2007; 253:74-88.

12. Xia X, Kung AL. Preferential binding of HIF-1 to transcriptionally active loci determines cell-type specific response to hypoxia. Genome Biol. 2009;10:R113.

13. Wenger RH, Kvietikova I, Rolfs A, Camenisch G, Gassmann M. Oxygen-regulated erythropoietin gene expression is dependent on a CpG methylation-free hypoxia-inducible factor-1 DNA-binding site. Eur J Biochem. 1998;253:771-7.

14. Bell AC, Felsenfeld G. Methylation of a CTCF-dependent boundary controls imprinted expression of the lgf2 gene. Nature. 2000;405:482-5.

15. Maurano MT, Wang H, John S, Shafer A, Canfield T, Lee K, Stamatoyannopoulos JA. Role of DNA methylation in modulating transcription factor occupancy. Cell Rep. 2015;12:1184-95.

16. Feng J, Liu T, Zhang Y: Using MACS to identify peaks from ChIP-Seq data. Curr Protoc Bioinformatics 2011, Chapter 2: Unit 214.

17. Griffon A, Barbier Q, Dalino J, van Helden J, Spicuglia S, Ballester B. Integrative analysis of public ChIP-seq experiments reveals a complex multi-cell regulatory landscape. Nucleic Acids Res. 2015;43:e27.

18. Menafra R, Brinkman AB, Matarese F, Franci G, Bartels SJ, Nguyen L, Shimbo T, Wade PA, Hubner NC, Stunnenberg HG. Genome-wide binding of MBD2 reveals strong preference for highly methylated loci. PLoS One. 2014;9:e99603.

19. Huang Y, Pastor WA, Shen Y, Tahiliani M, Liu DR, Rao A. The behaviour of 5-hydroxymethylcytosine in bisulfite sequencing. PLoS One. 2010;5:e8888.

20. Ahmed S, Wang A, Celius T, Matthews J. Zinc finger nuclease-mediated knockout of AHR or ARNT in human breast cancer cells abolishes basal and ligand-dependent regulation of CYP1B1 and differentially affects estrogen receptor a transactivation. Toxicol Sci. 2013;138:89-103.

21. Maltepe E, Schmidt JV, Baunoch D, Bradfield CA, Simon MC. Abnormal angiogenesis and responses to glucose and oxygen deprivation in mice lacking the protein ARNT. Nature. 1997;386:403.

22. Consortium EP. An integrated encyclopedia of DNA elements in the human genome. Nature. 2012;489:57-74.

23. Taberlay PC, Statham AL, Kelly TK, Clark SJ, Jones PA. Reconfiguration of nucleosome-depleted regions at distal regulatory elements accompanies DNA methylation of enhancers and insulators in cancer. Genome Res. 2014;24:1421-32. 
24. Wu X, Zhang Y. TET-mediated active DNA demethylation: mechanism, function and beyond. Nat Rev Genet. 2017;18:517.

25. Wu D, Potluri N, Lu J, Kim Y, Rastinejad F. Structural integration in hypoxia-inducible factors. Nature. 2015;524:303-8.

26. Mariani CJ, Vasanthakumar A, Madzo J, Yesilkanal A, Bhagat T, Yu Y, Bhattacharyya S, Wenger RH, Cohn SL, Nanduri J, et al. TET1-mediated hydroxymethylation facilitates hypoxic gene induction in neuroblastoma. Cell Rep. 2014;7:1343-52.

27. Tsumura A, Hayakawa T, Kumaki Y, Takebayashi S, Sakaue M, Matsuoka C, Shimotohno K, Ishikawa F, Li E, Ueda HR, et al. Maintenance of self-renewal ability of mouse embryonic stem cells in the absence of DNA methyltransferases Dnmt1, Dnmt3a and Dnmt3b. Genes Cells. 2006;11:805-14.

28. Beyrouthy MJ, Garner KM, Hever MP, Freemantle SJ, Eastman A, Dmitrovsky E, Spinella MJ. High DNA methyltransferase 3B expression mediates 5-aza-deoxycytidine hypersensitivity in testicular germ cell tumors. Cancer Res. 2009;69:9360-6.

29. Criscione SW, Zhang Y, Thompson W, Sedivy JM, Neretti N. Transcriptional landscape of repetitive elements in normal and cancer human cells. BMC Genomics. 2014;15:583.

30. Yang WR, Ardeljan D, Pacyna CN, Payer LM, Burns KH. SQulRE reveals locus-specific regulation of interspersed repeat expression. Nucleic Acids Res. 2019;47(5):e27.

31. Elvidge GP, Glenny L, Appelhoff RJ, Ratcliffe PJ, Ragoussis J, Gleadle JM. Concordant regulation of gene expression by hypoxia and 2-oxoglutarate-dependent dioxygenase inhibition the role of HIF-1a, HIF-2a, and other pathways. J Biol Chem. 2006;281:15215-26.

32. Blank CU, Haanen JB, Ribas A, Schumacher TN. CANCER IMMUNOLOGY. The "cancer immunogram". Science. 2016;352: 658-60.

33. Chiappinelli KB, Strissel PL, Desrichard A, Li H, Henke C, Akman B, Hein A, Rote NS, Cope LM, Snyder A, et al. Inhibiting DNA methylation causes an interferon response in cancer via dsRNA including endogenous retroviruses. Cell. 2015;162:974-86

34. Zitvogel L, Galluzzi L, Kepp O, Smyth MJ, Kroemer G. Type I interferons in anticancer immunity. Nat Rev Immunol. 2015; 15:405-14.

35. Leruste A, Tosello J, Ramos RN, Tauziède-Espariat A, Brohard S, Han Z-Y, Beccaria K, Andrianteranagna M, Caudana P, Nikolic J. Clonally expanded T cells reveal immunogenicity of rhabdoid tumors. Cancer Cell. 2019;36(6):597-612.e8.

36. Rooney MS, Shukla SA, Wu CJ, Getz G, Hacohen N. Molecular and genetic properties of tumors associated with local immune cytolytic activity. Cell. 2015;160:48-61.

37. Buffa FM, Harris AL, West CM, Miller CJ. Large meta-analysis of multiple cancers reveals a common, compact and highly prognostic hypoxia metagene. Br J Cancer. 2010;102:428-35.

38. Turajili S, Litchfield K, Xu H, Rosenthal R, McGranahan N, Reading JL, Wong YNS, Rowan A, Kanu N, Al Bakir M, et al. Insertion-and-deletion-derived tumour-specific neoantigens and the immunogenic phenotype: a pan-cancer analysis. Lancet Oncol. 2017;18:1009-21.

39. Bian S, Hou Y, Zhou X, Li X, Yong J, Wang Y, Wang W, Yan J, Hu B, Guo H, et al. Single-cell multiomics sequencing and analyses of human colorectal cancer. Science. 2018;362:1060-3.

40. Roulois D, Loo Yau H, Singhania R, Wang Y, Danesh A, Shen SY, Han H, Liang G, Jones PA, Pugh TJ, et al. DNA-Demethylating agents target colorectal cancer cells by inducing viral mimicry by endogenous transcripts. Cell. 2015;162:961-73.

41. Kim K, Skora A, Li Z, Tam A, Diaz L, Papadopolous N, Blosser L, Kinzler K, Vogelstein B, Zhou S. Eradication of metastatic mouse cancers resistant to immune checkpoint blockade by suppression of myeloid-derived cells. J Immunother Cancer. 2014;2:P267.

42. Ngiow SF, Young A, Jacquelot N, Yamazaki T, Enot D, Zitvogel L, Smyth MJ: A threshold level of intratumor CD8+ T cell PD1 expression dictates therapeutic response to anti-PD1. Cancer Res 2015;75(18):3800-11.

43. Charoentong P, Finotello F, Angelova M, Mayer C, Efremova M, Rieder D, Hackl H, Trajanoski Z. Pan-cancer immunogenomic analyses reveal genotype-immunophenotype relationships and predictors of response to checkpoint blockade. Cell Rep. 2017:18:248-62.

44. Riggs AD. X inactivation, differentiation, and DNA methylation. Cytogenet Cell Genet. 1975;14:9-25.

45. Holliday R, Pugh JE. DNA modification mechanisms and gene activity during development. Science. 1975;187:226-32.

46. Vanharanta S, Shu W, Brenet F, Hakimi AA, Heguy A, Viale A, Reuter VE, Hsieh JJ, Scandura JM, Massague J. Epigenetic expansion of VHL-HIF signal output drives multiorgan metastasis in renal cancer. Nat Med. 2013;19:50-6.

47. Partch $\mathrm{CL}$, Gardner KH. Coactivators necessary for transcriptional output of the hypoxia inducible factor, HIF, are directly recruited by ARNT PAS-B. Proc Natl Acad Sci U S A. 2011:108:7739-44.

48. Brocks D, Schmidt CR, Daskalakis M, Jang HS, Shah NM, Li D, Li J, Zhang B, Hou Y, Laudato S. DNMT and HDAC inhibitors induce cryptic transcription start sites encoded in long terminal repeats. Nat Genet. 2017:49:1052

49. Trizzino M, Park Y, Holsbach-Beltrame M, Aracena K, Mika K, Caliskan M, Perry GH, Lynch VJ, Brown CD. Transposable elements are the primary source of novelty in primate gene regulation. Genome Res. 2017;27:1623-33.

50. Simonti CN, Capra JA, Pavličev M. Transposable element exaptation into regulatory regions is rare, influenced by evolutionary age, and subject to pleiotropic constraints. Mol Biol Evol. 2017;34:2856-69.

51. Navarro C. The mobile world of transposable elements. Trends Genet. 2017;33:771-2.

52. Trizzino M, Kapusta A, Brown CD. Transposable elements generate regulatory novelty in a tissue-specific fashion. BMC Genomics. 2018;19:468.

53. Simon MC, Keith B. The role of oxygen availability in embryonic development and stem cell function. Nat Rev Mol Cell Biol. 2008:9:285.

54. Rodriguez-Terrones D, Torres-Padilla M-E. Nimble and ready to mingle: transposon outbursts of early development. Trends Genet. 2018:34(10):806-20

55. Reik W, Dean W, Walter J. Epigenetic reprogramming in mammalian development. Science. 2001;293:1089-93.

56. Sheng W, LaFleur MW, Nguyen TH, Chen S, Chakravarthy A, Conway JR, Li Y, Chen H, Yang H, Hsu P-H. LSD1 ablation stimulates anti-tumor immunity and enables checkpoint blockade. Cell. 2018;174(3):549-563.e19.

57. Hu X, Zhang L, Mao SQ, Li Z, Chen J, Zhang RR, Wu HP, Gao J, Guo F, Liu W, et al. Tet and TDG mediate DNA demethylation essential for mesenchymal-to-epithelial transition in somatic cell reprogramming. Cell Stem Cell. 2014;14:512-22.

58. Sakaue M, Ohta H, Kumaki Y, Oda M, Sakaide Y, Matsuoka C, Yamagiwa A, Niwa H, Wakayama T, Okano M. DNA methylation is dispensable for the growth and survival of the extraembryonic lineages. Curr Biol. 2010;20:1452-7.

59. Galle E, Thienpont B, Cappuyns S, Venken T, Busschaert P, Van Haele M, Van Cutsem E, Roskams T, van Pelt J, Verslype C, et al. DNA methylation-driven EMT is a common mechanism of resistance to various therapeutic agents in cancer. Clin Epigenetics. 2020;12:27. 
60. Bogu GK, Vizan P, Stanton LW, Beato M, Di Croce L, Marti-Renom MA. Chromatin and RNA maps reveal regulatory long noncoding RNAs in mouse. Mol Cell Biol. 2015;36:809-19.

61. Pertea M, Pertea GM, Antonescu CM, Chang T-C, Mendell JT, Salzberg SL. StringTie enables improved reconstruction of a transcriptome from RNA-seq reads. Nat Biotechnol. 2015;33:290.

62. Anders S, Pyl PT, Huber W. HTSeq-a Python framework to work with high-throughput sequencing data. Bioinformatics. 2015;31:166-9.

63. Alexa A, Rahnenfuhrer J. topGO: enrichment analysis for gene ontology. R package version 2120; 2010.

64. Pettersen EF, Goddard TD, Huang CC, Couch GS, Greenblatt DM, Meng EC, Ferrin TE. UCSF chimera--a visualization system for exploratory research and analysis. J Comput Chem. 2004;25:1605-12.

65. Zhao H, Thienpont B, Yesilyurt BT, Moisse M, Reumers J, Coenegrachts L, Sagaert X, Schrauwen S, Smeets D, Matthijs G Mismatch repair deficiency endows tumors with a unique mutation signature and sensitivity to DNA double-strand breaks. Elife. 2014;3:e02725.

66. Lambrechts D, Wauters E, Boeckx B, Aibar S, Nittner D, Burton O, Bassez A, Decaluwe H, Pircher A, Van den Eynde K, et al. Phenotype molding of stromal cells in the lung tumor microenvironment. Nat Med. 2018;24:1277-89.

67. D'Anna F, Dyck LV, Xiong J, Zhao H, Berrens RV, Bieniasz-Krzywiec P, Chandra V, Schoonjans L, Matthews J, De Smedt J, et al: DNA Methylation Repels Binding of HIF Transcription Factors to Maintain Tumour Immunotolerance. Dataset. Gene Expression Omnibus (GSE85356) 2020.

68. Habibi E, Brinkman Arie B, Arand J, Kroeze Leonie I, Kerstens Hindrik HD, Matarese F, Lepikhov K, Gut M, Brun-Heath I, Hubner Nina C, et al. Whole-genome bisulfite sequencing of two distinct interconvertible DNA methylomes of mouse embryonic stem cells. Cell Stem Cell. 2013;13(3):360-9.

\section{Publisher's Note}

Springer Nature remains neutral with regard to jurisdictional claims in published maps and institutional affiliations.

\section{Ready to submit your research? Choose BMC and benefit from:}

- fast, convenient online submission

- thorough peer review by experienced researchers in your field

- rapid publication on acceptance

- support for research data, including large and complex data types

- gold Open Access which fosters wider collaboration and increased citations

- maximum visibility for your research: over $100 \mathrm{M}$ website views per year

At $\mathrm{BMC}$, research is always in progress.

Learn more biomedcentral.com/submissions 